\title{
Spongian Diterpenes Including One with a Rearranged Skeleton from the Marine Sponge Spongia officinalis
}

Qian Chen, ${ }^{\dagger}, \perp$ Qiqi Mao, ${ }^{\dagger, \perp}$ Miao Bao, ${ }^{\dagger}$ Yongxiao Mou, ${ }^{\dagger}$ Chengyan Fang, ${ }^{\dagger}$ Min Zhao,${ }^{\dagger}$

Wei Jiang,,${ }^{\ddagger}$ Xia Yu,${ }^{\S}$ Chaojie Wang,${ }^{\dagger}$ Lishang Dai, ${ }^{\dagger}$ Wenfei He,${ }^{\dagger}$ Jianyong Dong, ${ }^{\dagger}$

Jianzhang $\mathrm{Wu}, *, \dagger$ Pengcheng Yan*,†

†School of Pharmaceutical Sciences, Wenzhou Medical University, Wenzhou,

Zhejiang 325035, People's Republic of China

\#School of Environmental Science and Engineering, Yangzhou University, Yangzhou,

Jiangsu 225127, People's Republic of China

§Xiangya School of Pharmaceutical Sciences, Central South University, Changsha,

Hunan 410013, People's Republic of China

Corresponding Authors

*E-mail (J. Wu): wjzwzmu@163.com.

*Tel (P. Yan): +86-577-86699572; E-mail: yanpc@wmu.edu.cn.

${ }^{\perp}$ Q. Chen and Q. Mao made equal contribution to this work. 


\section{List of supporting information}

Figure S1. ${ }^{1} \mathrm{H}$ NMR spectrum $(500 \mathrm{MHz})$ of compound 1 in acetone- $d_{6}$.

Figure S2. ${ }^{13} \mathrm{C}$ NMR spectrum $(125 \mathrm{MHz})$ of compound 1 in acetone- $d_{6}$.

Figure S3. HMQC spectrum of compound 1 in acetone- $d_{6}$.

Figure S4. HMBC spectrum of compound 1 in acetone- $d_{6}$.

Figure S5. COSY spectrum of compound 1 in acetone- $d_{6}$.

Figure S6. NOESY spectrum of compound 1 in acetone- $d_{6}$.

Figure S7. HRESIMS spectrum of compound 1.

Figure S8. ${ }^{1} \mathrm{H}$ NMR spectrum $(600 \mathrm{MHz})$ of compound 2 in acetone- $d_{6}$.

Figure S9. ${ }^{13} \mathrm{C}$ NMR spectrum $(150 \mathrm{MHz})$ of compound 2 in acetone- $d_{6}$.

Figure S10. HMQC spectrum of compound 2 in acetone- $d_{6}$.

Figure S11. HMBC spectrum of compound 2 in acetone- $d_{6}$.

Figure S12. COSY spectrum of compound 2 in acetone- $d_{6}$.

Figure S13. NOESY spectrum of compound $\mathbf{2}$ in acetone- $d_{6}$.

Figure S14. HRESIMS spectrum of compound 2.

Figure S15. ${ }^{1} \mathrm{H}$ NMR spectrum $(500 \mathrm{MHz})$ of compound 3 in acetone- $d_{6}$.

Figure S16. ${ }^{13} \mathrm{C}$ NMR spectrum $(125 \mathrm{MHz})$ of compound 3 in acetone- $d_{6}$.

Figure S17. HMQC spectrum of compound 3 in acetone- $d_{6}$.

Figure S18. HMBC spectrum of compound 3 in acetone- $d_{6}$.

Figure S19. COSY spectrum of compound 3 in acetone- $d_{6}$.

Figure S20. NOESY spectrum of compound $\mathbf{3}$ in acetone- $d_{6}$.

Figure S21. HRESIMS spectrum of compound 3.

Figure S22. ${ }^{1} \mathrm{H}$ NMR spectrum $(500 \mathrm{MHz})$ of compound 4 in acetone- $d_{6}$.

Figure S23. ${ }^{13} \mathrm{C}$ NMR spectrum $(125 \mathrm{MHz})$ of compound 4 in acetone- $d_{6}$.

Figure S24. HMQC spectrum of compound 4 in acetone- $d_{6}$.

Figure S25. HMBC spectrum of compound 4 in acetone- $d_{6}$.

Figure S26. COSY spectrum of compound 4 in acetone- $d_{6}$.

Figure S27. NOESY spectrum of compound 4 in acetone- $d_{6}$.

Figure S28. HRESIMS spectrum of compound 4.

Figure S29. ${ }^{1} \mathrm{H}$ NMR spectrum $(600 \mathrm{MHz})$ of compound 5 in acetone- $d_{6}$. 
Figure S30. ${ }^{13} \mathrm{C}$ NMR spectrum $(150 \mathrm{MHz})$ of compound 5 in acetone- $d_{6}$.

Figure S31. HMQC spectrum of compound 5 in acetone- $d_{6}$.

Figure S32. HMBC spectrum of compound $\mathbf{5}$ in acetone- $d_{6}$.

Figure S33. COSY spectrum of compound 5 in acetone- $d_{6}$.

Figure S34. NOESY spectrum of compound 5 in acetone- $d_{6}$.

Figure S35. HRESIMS spectrum of compound 5.

Figure S36. Experimental and calculated ECD spectra for 1.

Figure S37. Key NOE correlations and computer-generated models using MM2 force field calculations for $\mathbf{2}$ and $\mathbf{3}$.

Figure S38. ECD spectra of 2-5, octant rules of 2-4, and helicity rule of 5 . 
Figure S1. ${ }^{1} \mathrm{H}$ NMR spectrum $(500 \mathrm{MHz})$ of compound 1 in acetone- $d_{6}$.

MQ01D31B, 1H, acetone-d6, 500MHz

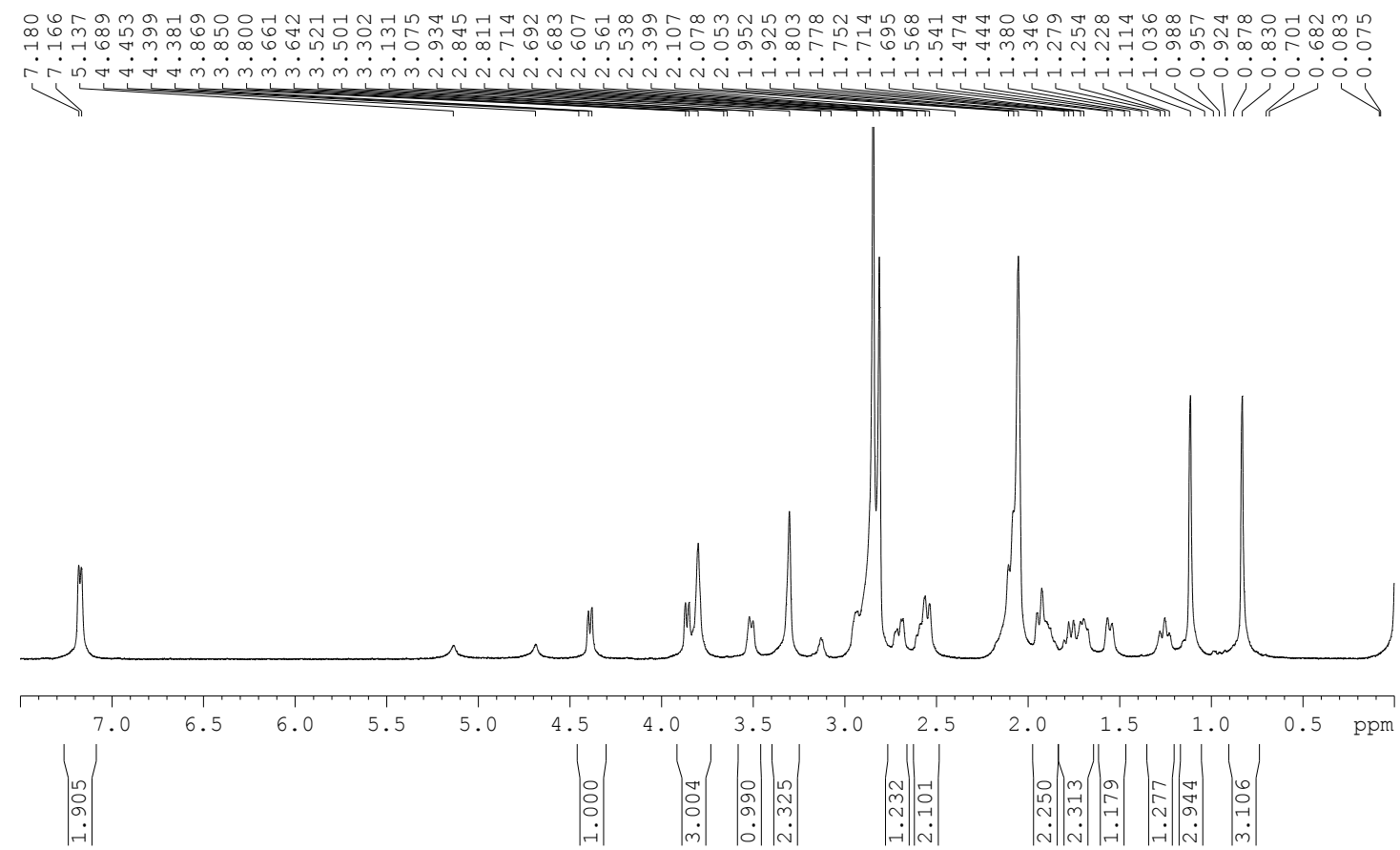

Figure S2. ${ }^{13} \mathrm{C}$ NMR spectrum $(125 \mathrm{MHz})$ of compound $\mathbf{1}$ in acetone- $d_{6}$. MQ01D31B, 13C, acetone-d6, 125MHz

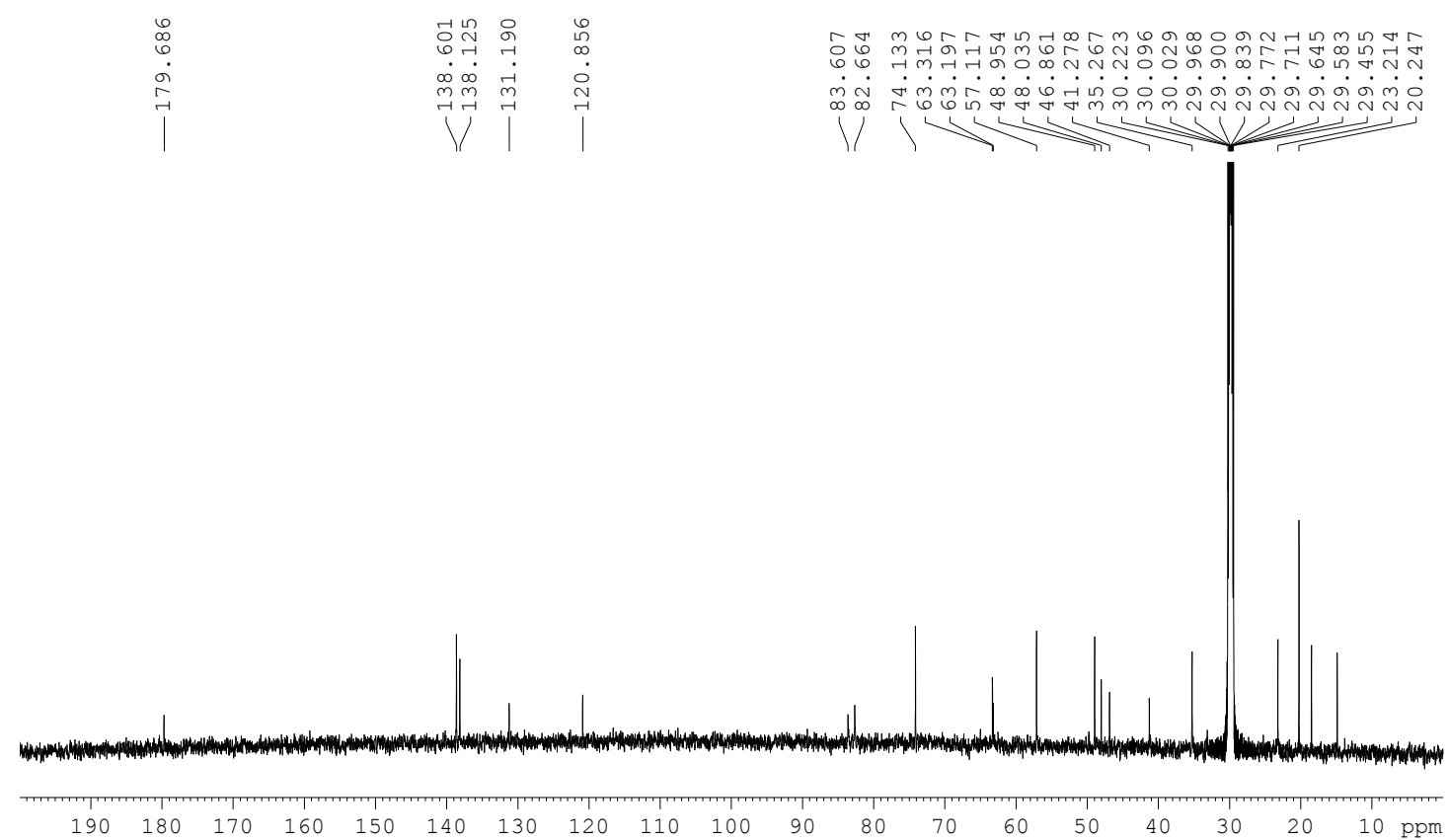


Figure S3. HMQC spectrum of compound 1 in acetone- $d_{6}$.

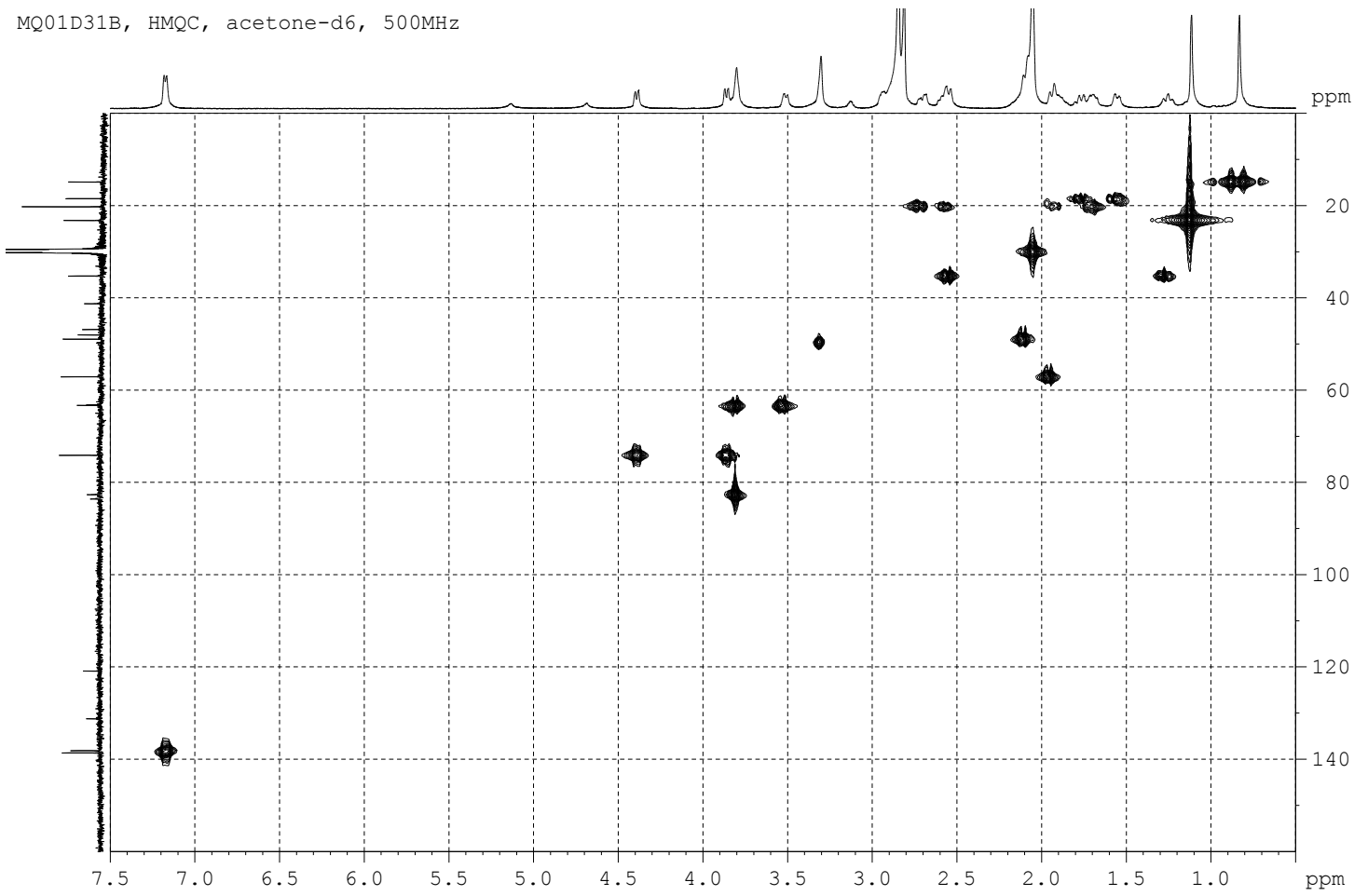

Figure S4. HMBC spectrum of compound 1 in acetone- $d_{6}$.

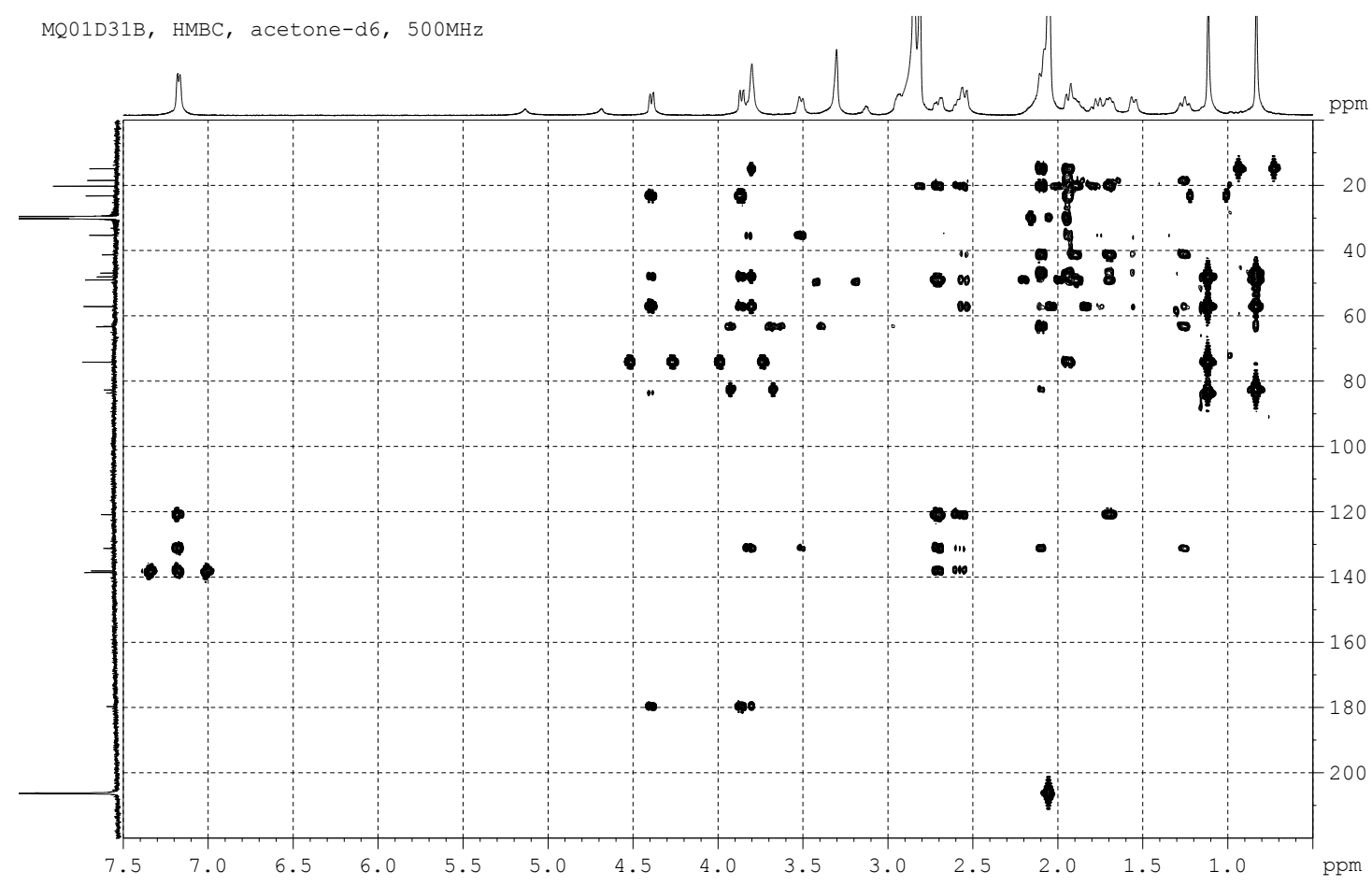


Figure S5. COSY spectrum of compound 1 in acetone- $d_{6}$.

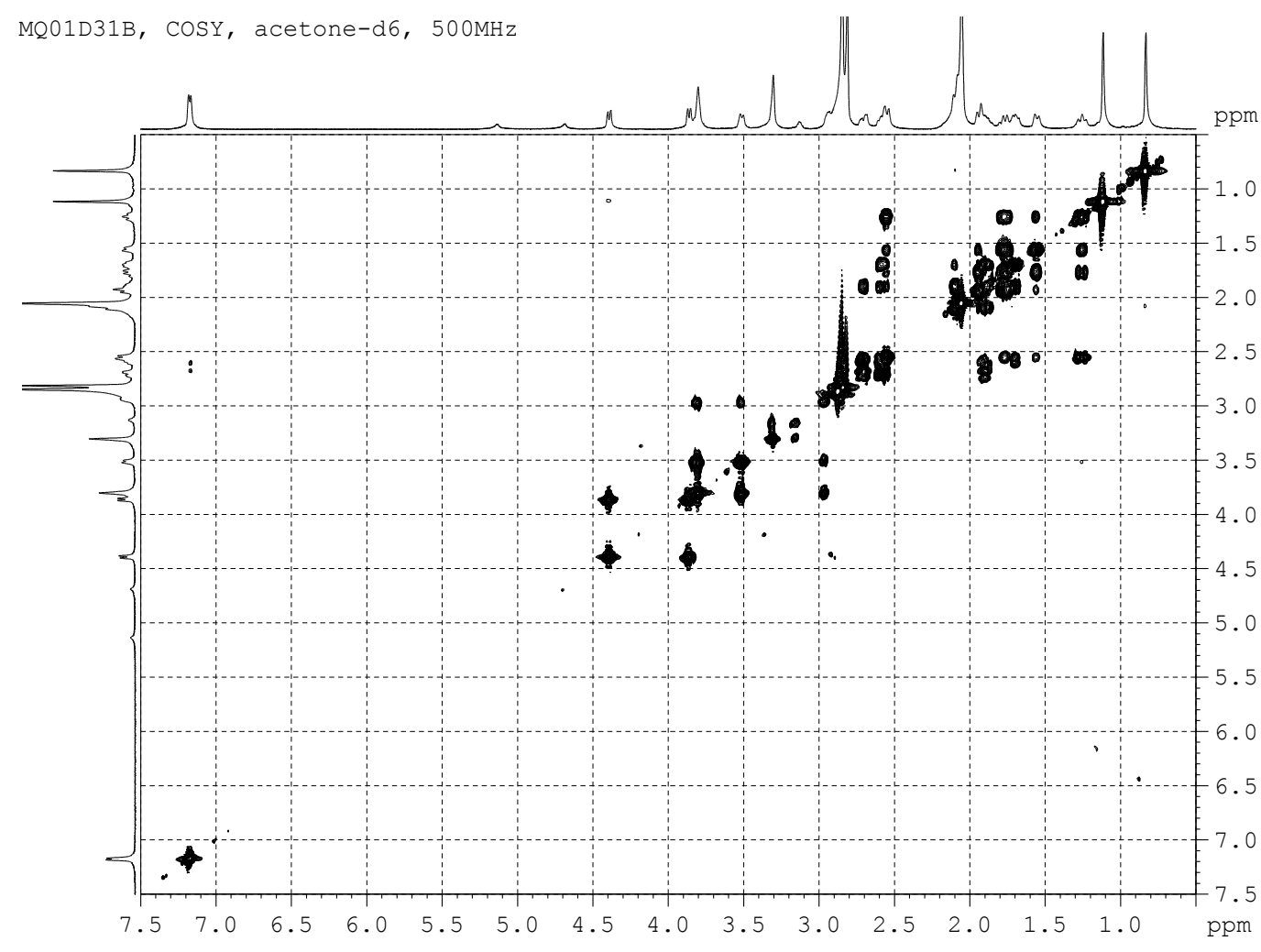

Figure S6. NOESY spectrum of compound 1 in acetone- $d_{6}$.

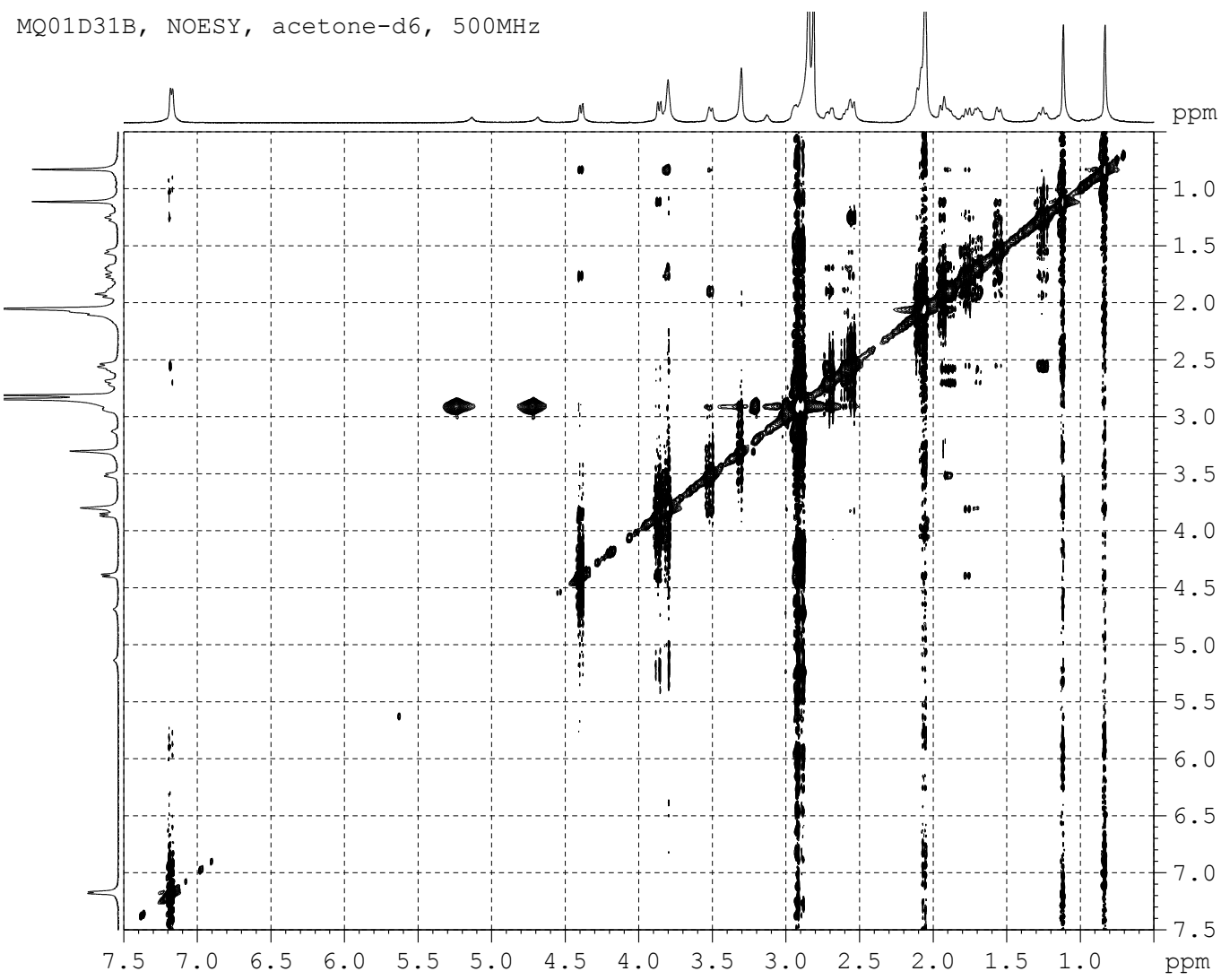


Figure S7. HRESIMS spectrum of compound 1.

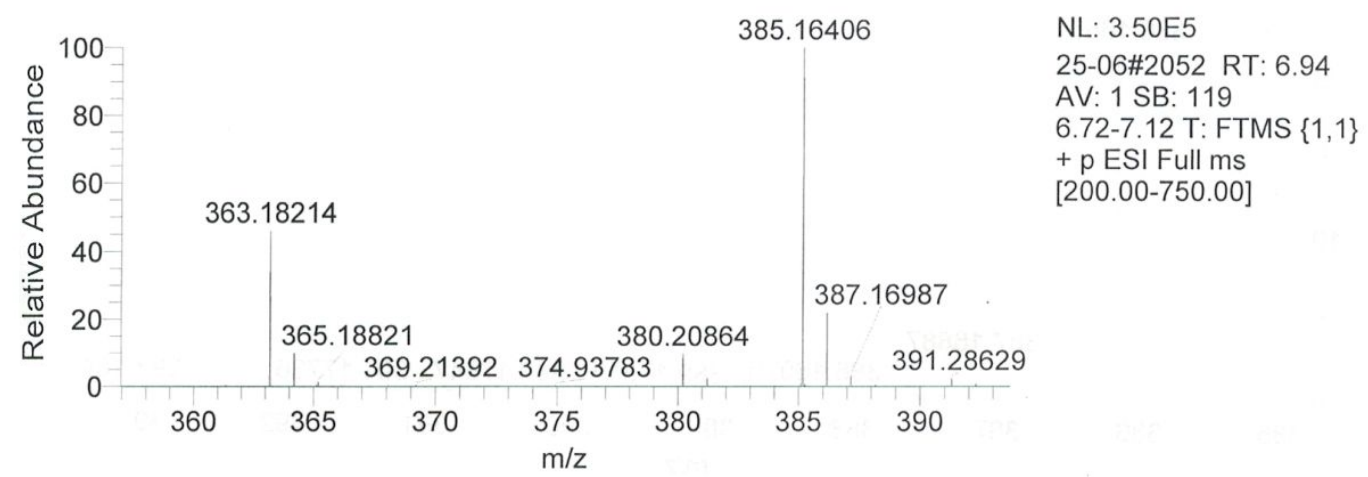

Figure S8. ${ }^{1} \mathrm{H}$ NMR spectrum $(600 \mathrm{MHz})$ of compound 2 in acetone- $d_{6}$.

MQ01D026A, 1H, acetone, 600MHz

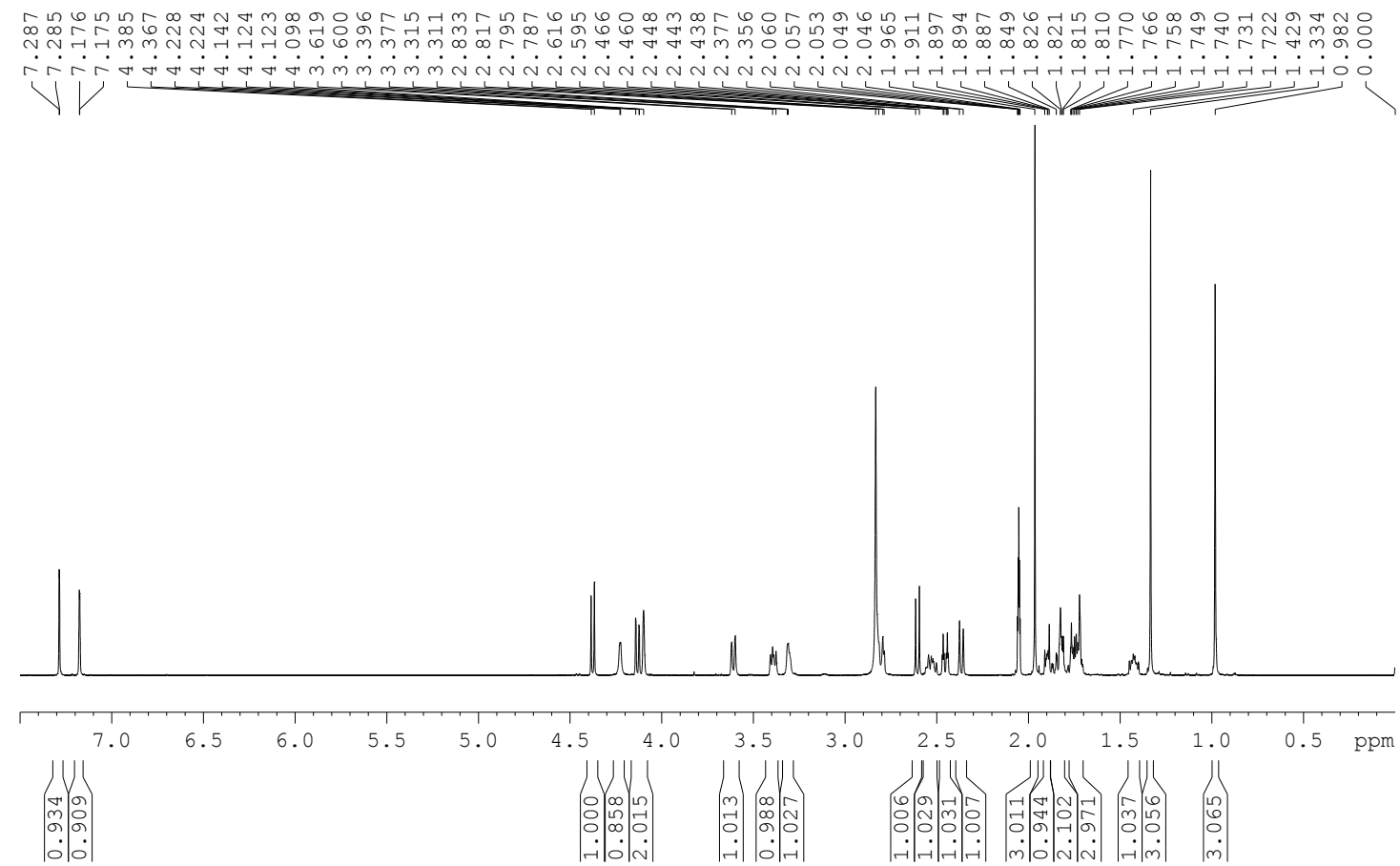


Figure S9. ${ }^{13} \mathrm{C}$ NMR spectrum $(150 \mathrm{MHz})$ of compound 2 in acetone- $d_{6}$.

MQ01D026A, 13C, acetone, 150MHz

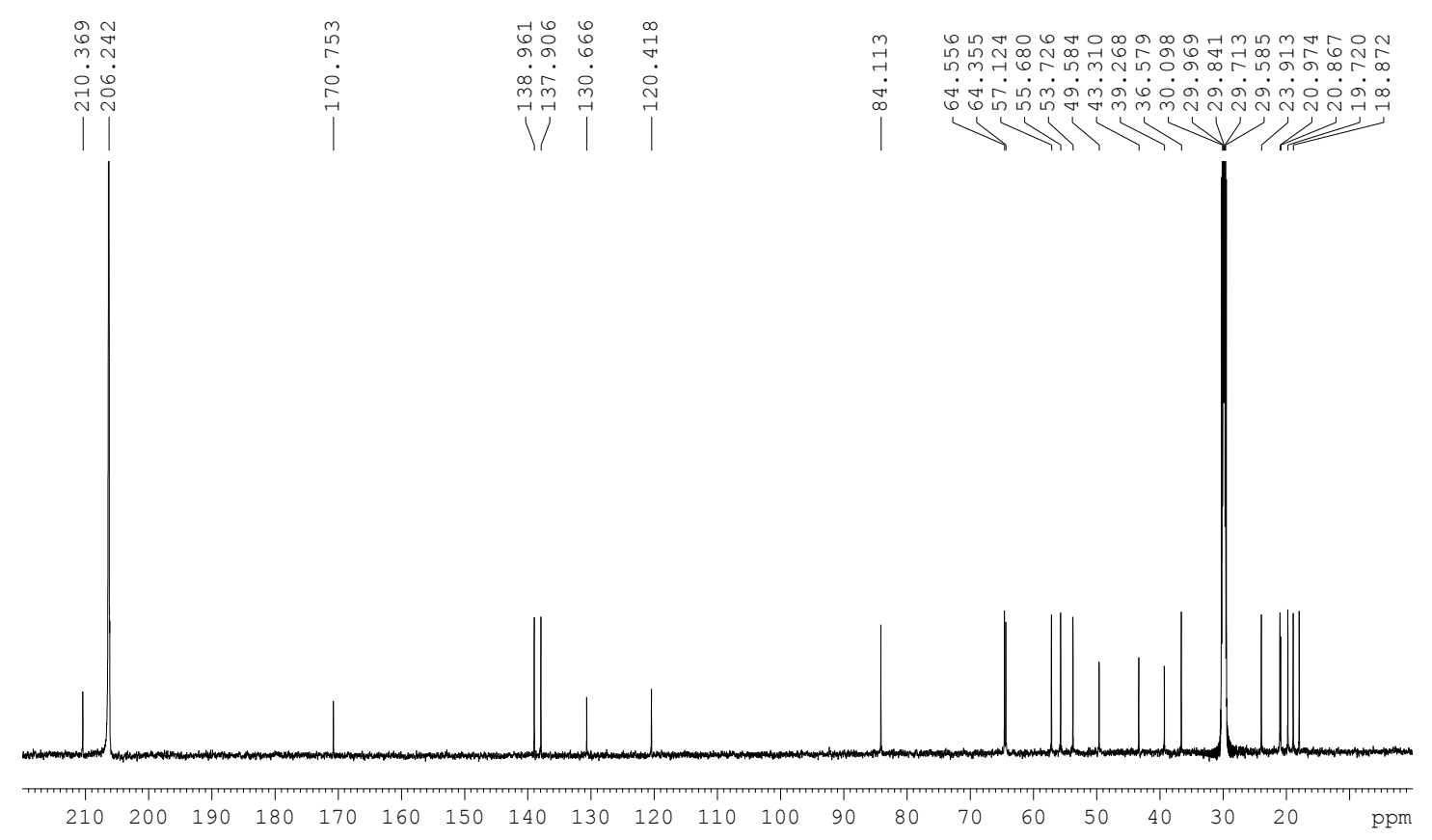

Figure S10. HMQC spectrum of compound 2 in acetone- $d_{6}$.

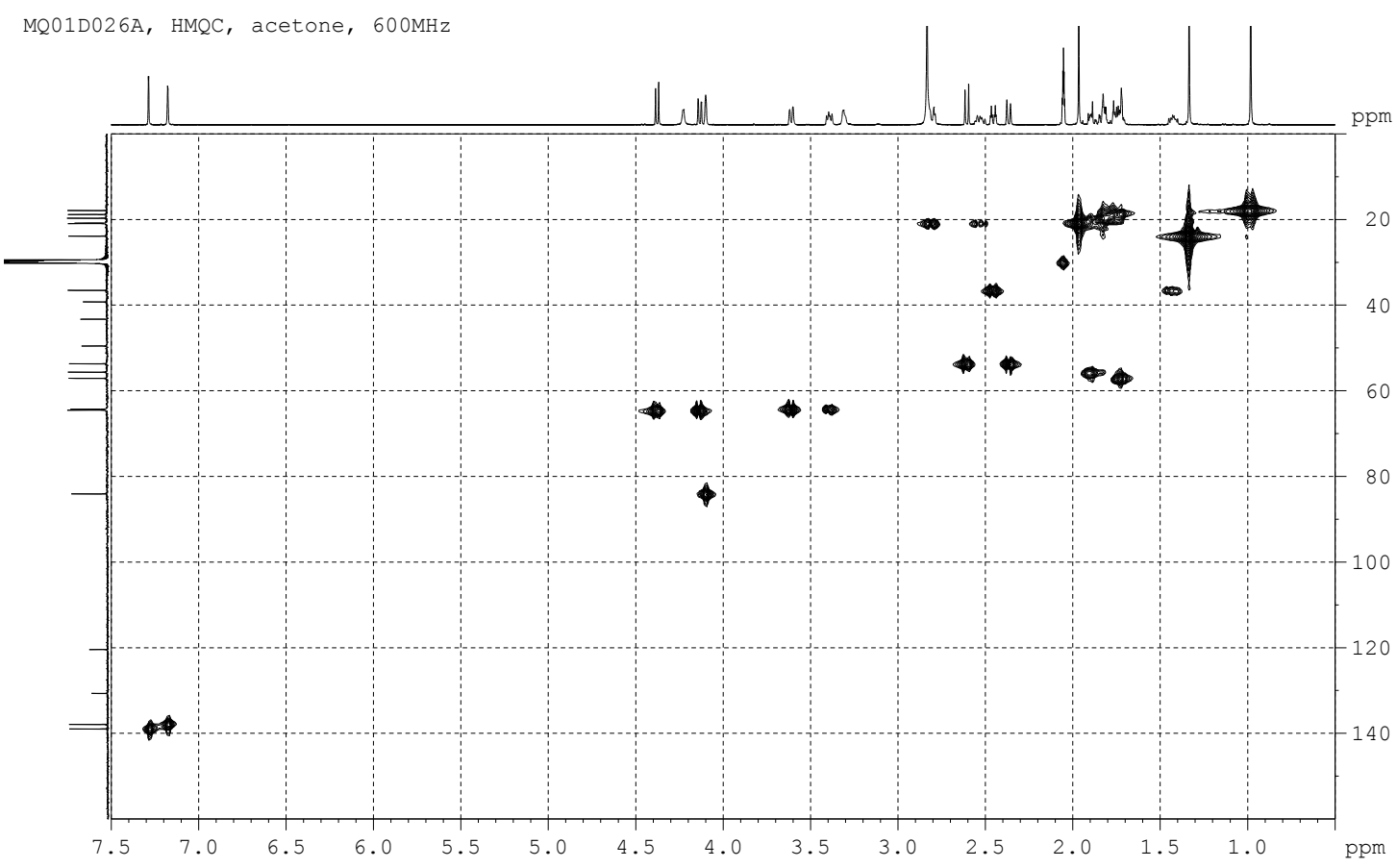


Figure S11. HMBC spectrum of compound $\mathbf{2}$ in acetone- $d_{6}$.

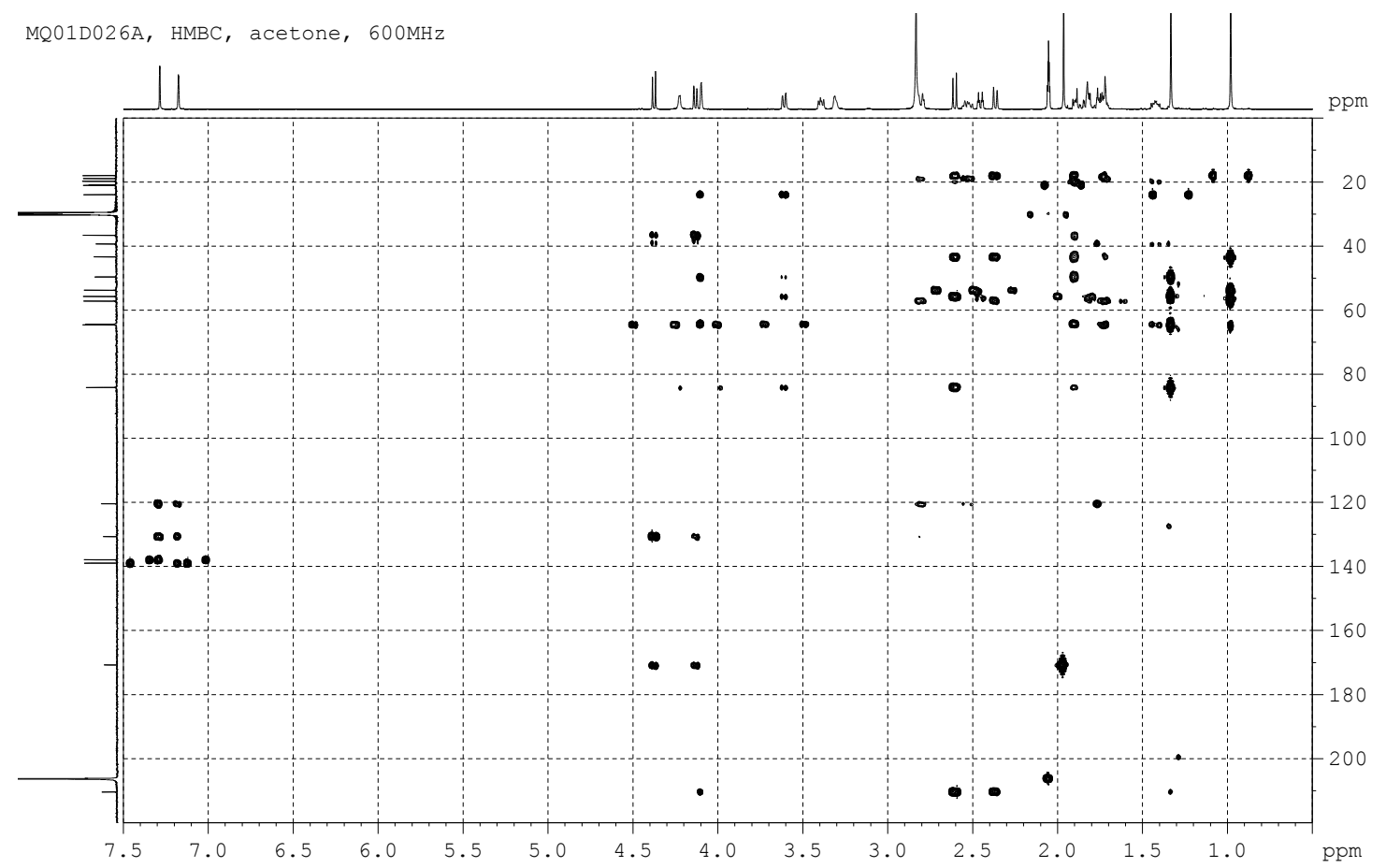

Figure S12. COSY spectrum of compound 2 in acetone- $d_{6}$.




Figure S13. NOESY spectrum of compound 2 in acetone- $d_{6}$.

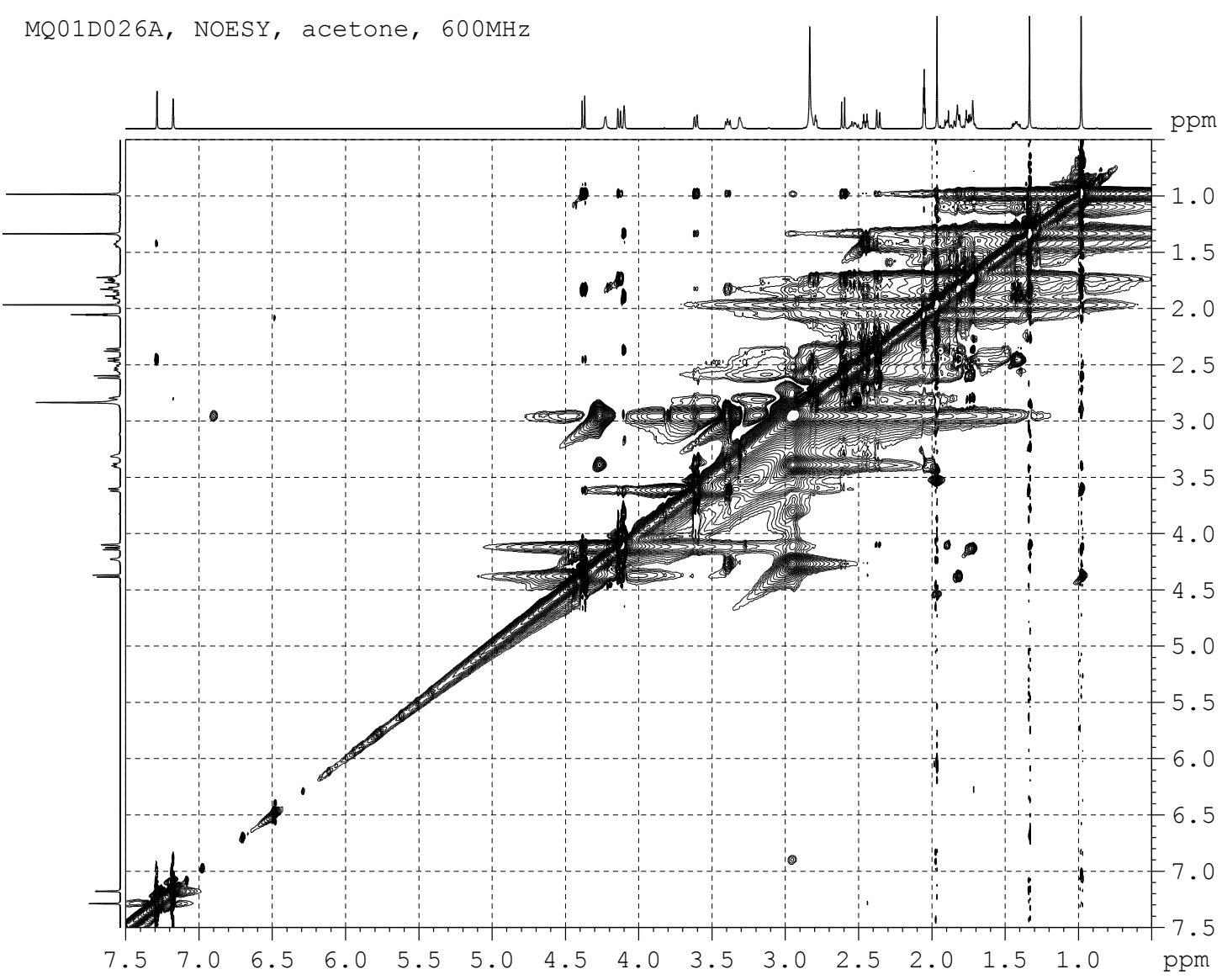

Figure S14. HRESIMS spectrum of compound 2.

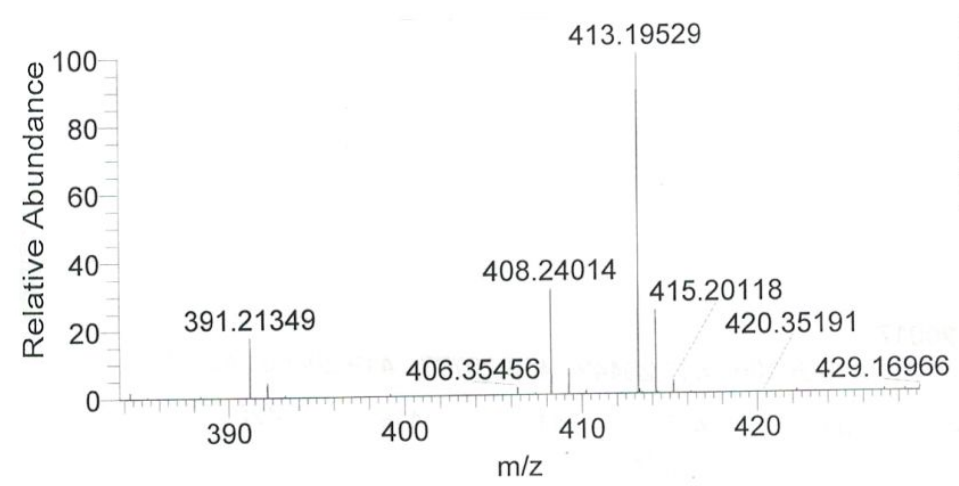

$\mathrm{NL}: 8.34 \mathrm{E} 5$

23-03\#2346-2373 RT:

7.93-8.02 AV: 28 SB: 1645

4.70-7.90 8.07-10.43 T:

FTMS $\{1,1\}+p$ ESI Full ms

[200.00-750.00]

$\mathrm{ppm}$ 
Figure $\mathbf{S 1 5} .{ }^{1} \mathrm{H}$ NMR spectrum $(500 \mathrm{MHz})$ of compound $\mathbf{3}$ in acetone- $d_{6}$.

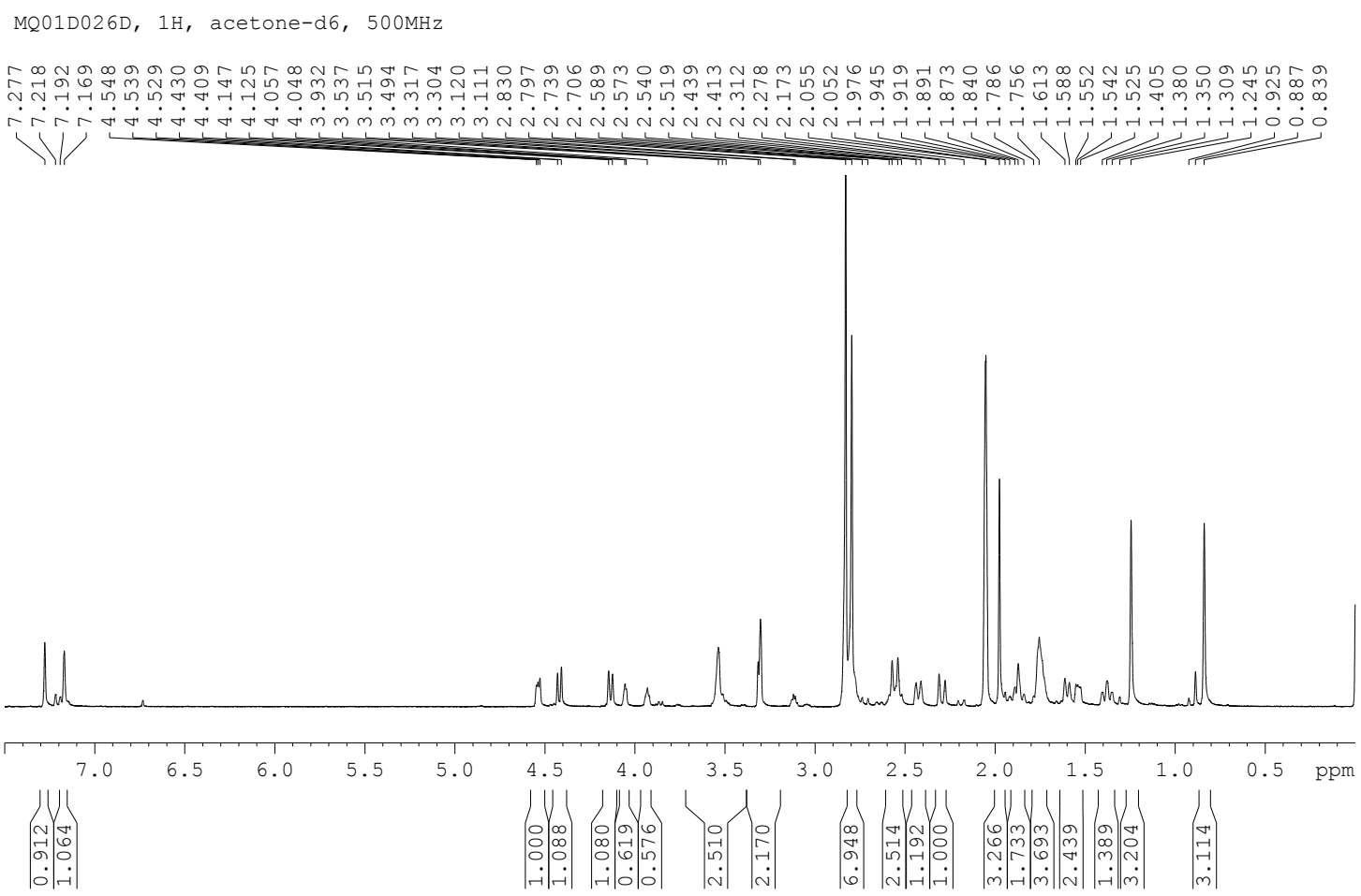

Figure S16. ${ }^{13} \mathrm{C}$ NMR spectrum $(125 \mathrm{MHz})$ of compound 3 in acetone- $d_{6}$. MQ01D026D, 13C, acetone-d6, 125MHz

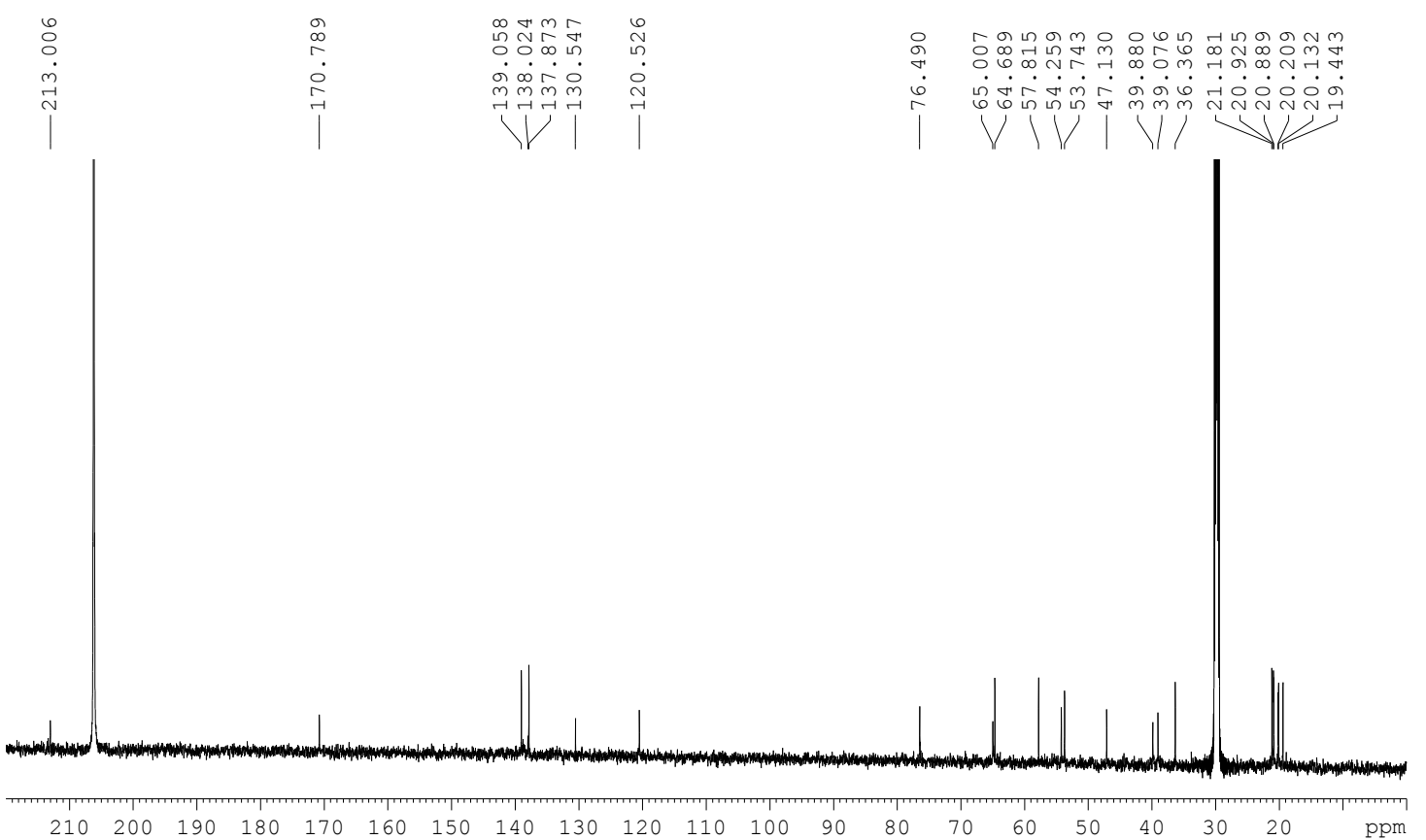


Figure S17. HMQC spectrum of compound 3 in acetone- $d_{6}$.

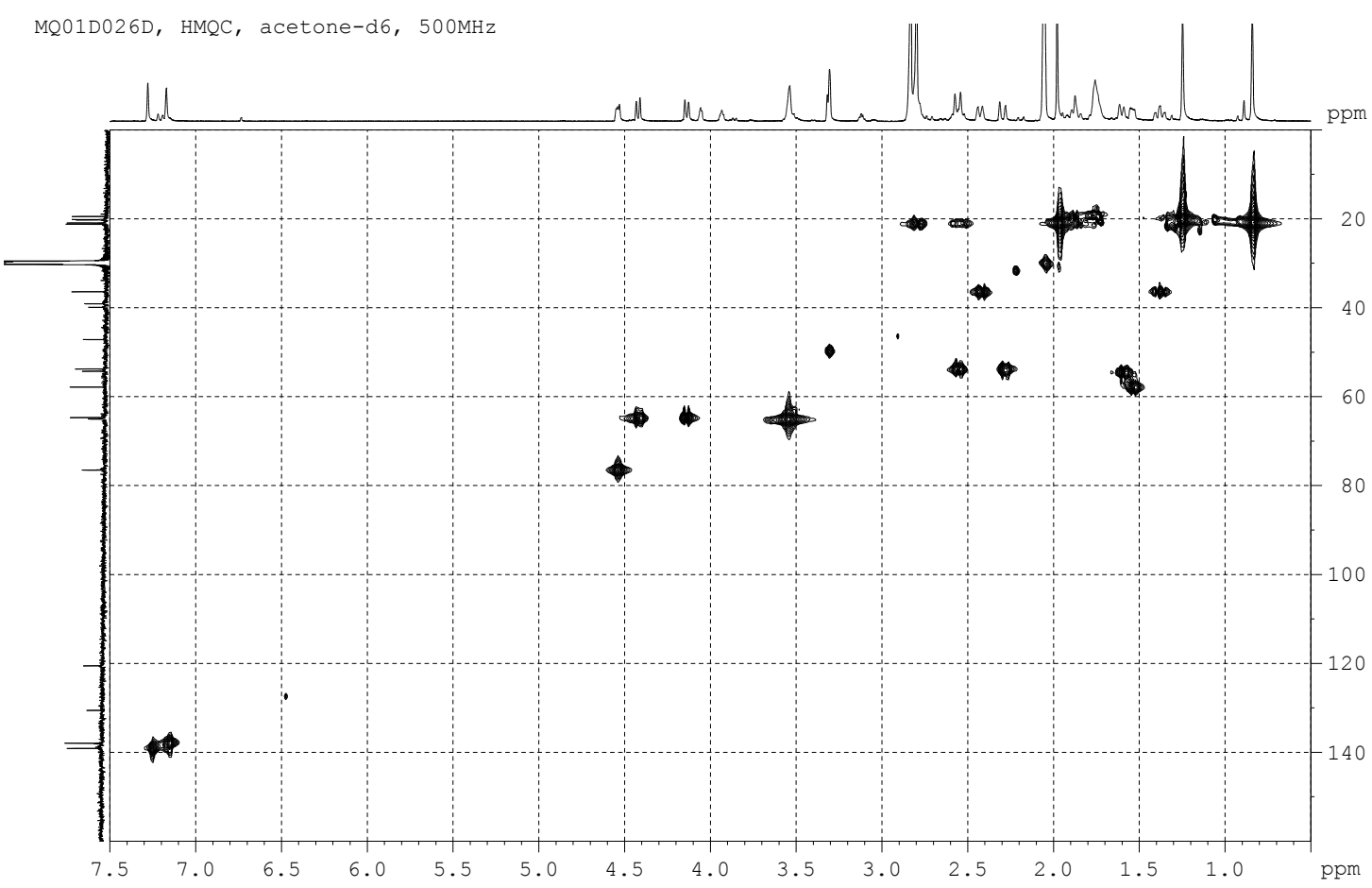

Figure S18. HMBC spectrum of compound 3 in acetone- $d_{6}$.

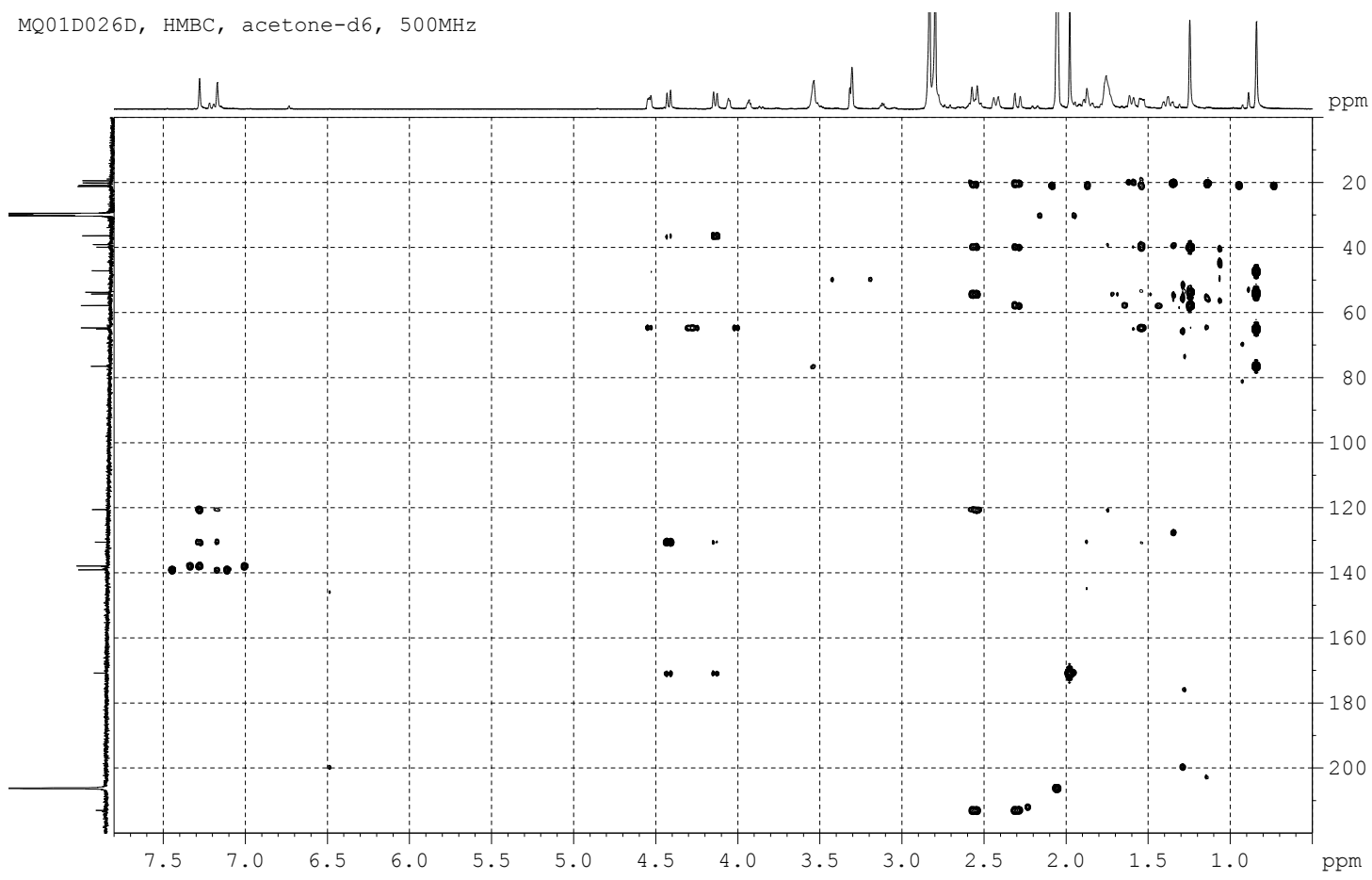


Figure S19. COSY spectrum of compound $\mathbf{3}$ in acetone- $d_{6}$.

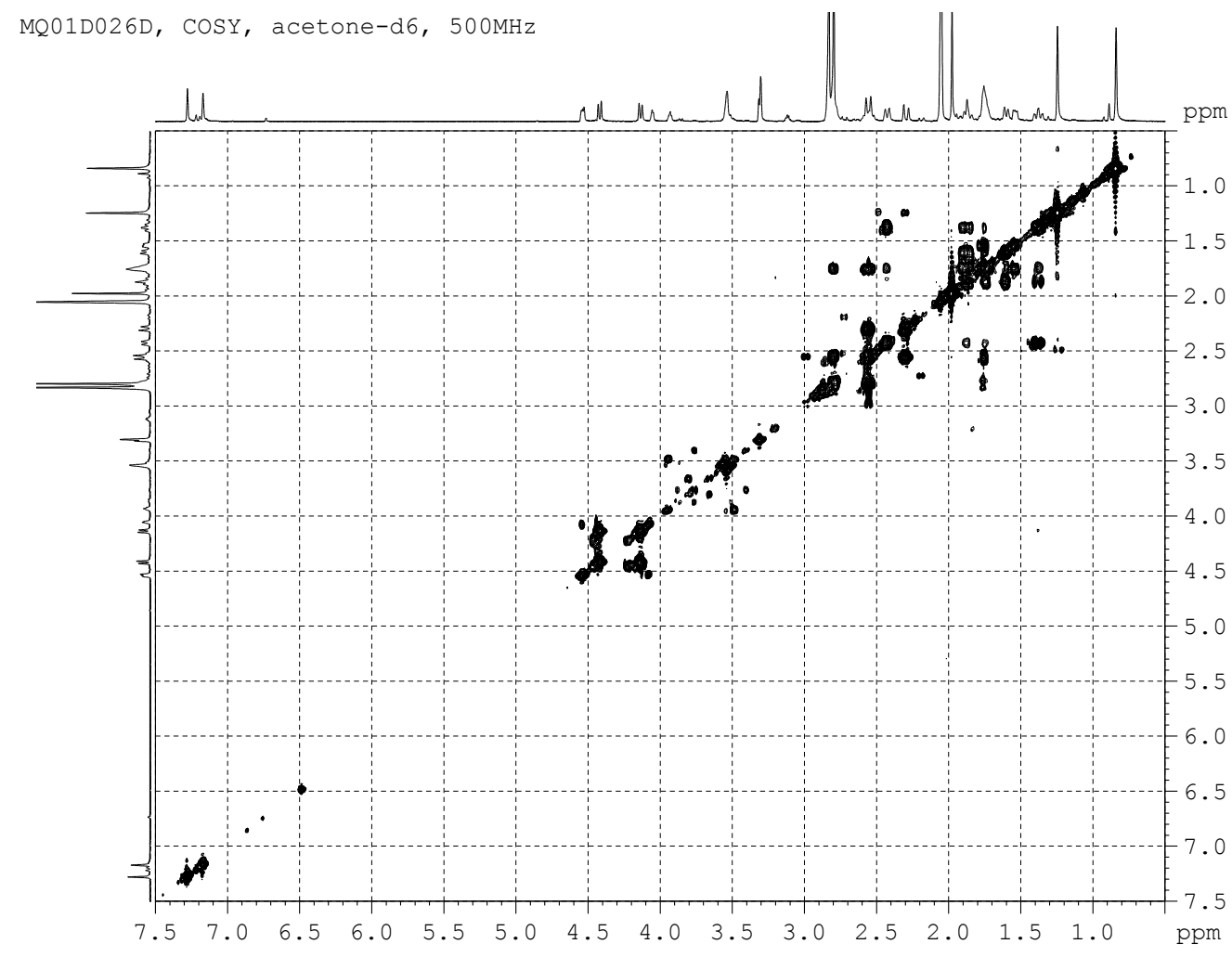

Figure S20. NOESY spectrum of compound 3 in acetone- $d_{6}$.

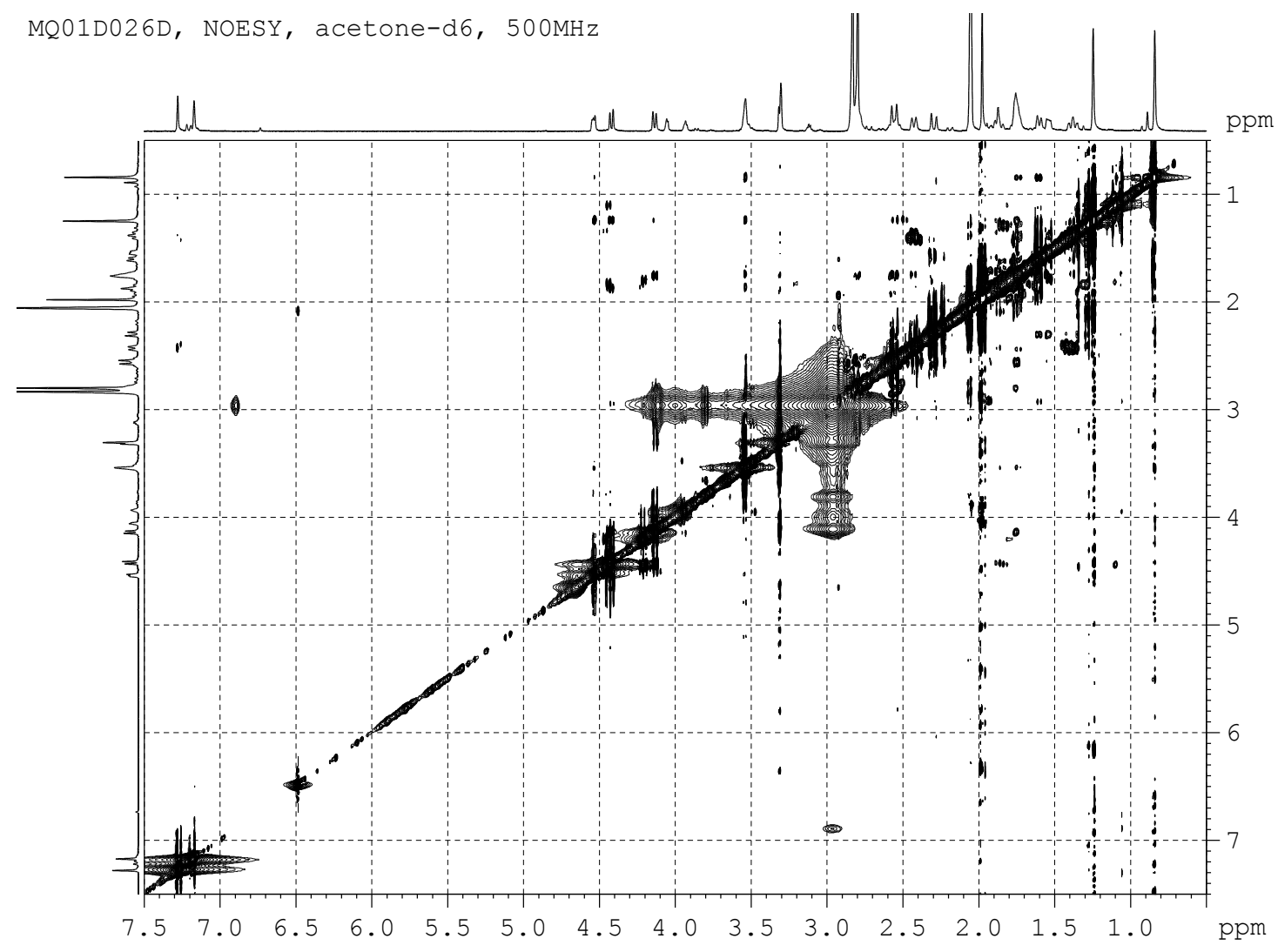


Figure S21. HRESIMS spectrum of compound 3.

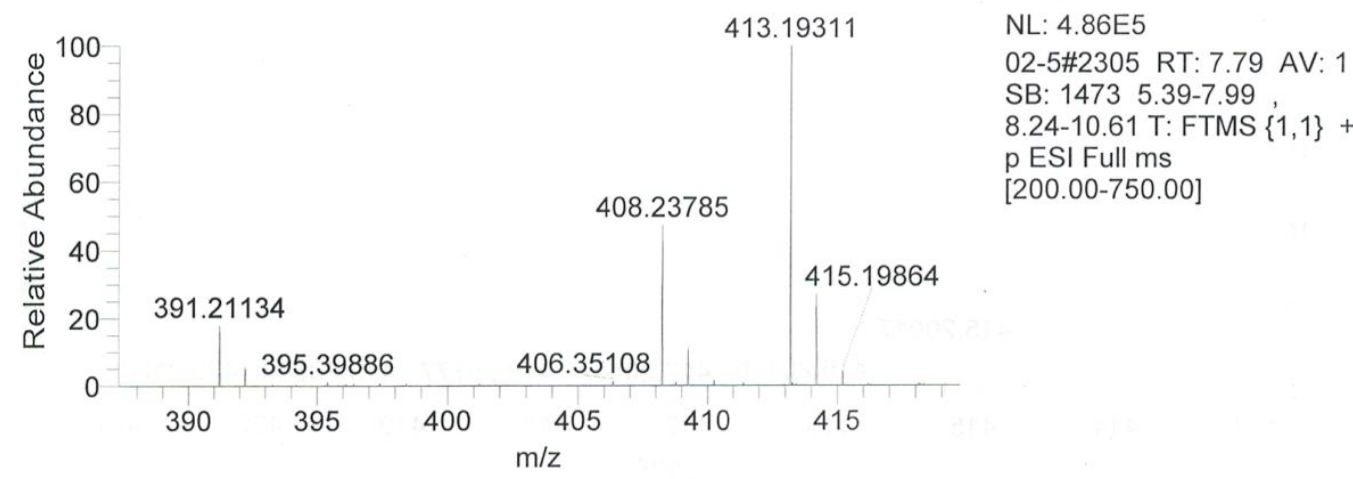

Figure S22. ${ }^{1} \mathrm{H}$ NMR spectrum $(500 \mathrm{MHz})$ of compound 4 in acetone- $d_{6}$.

MQ01D031C, 1H, acetone-d6, 500MHz

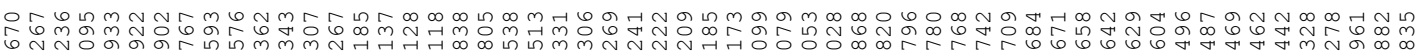
ம்

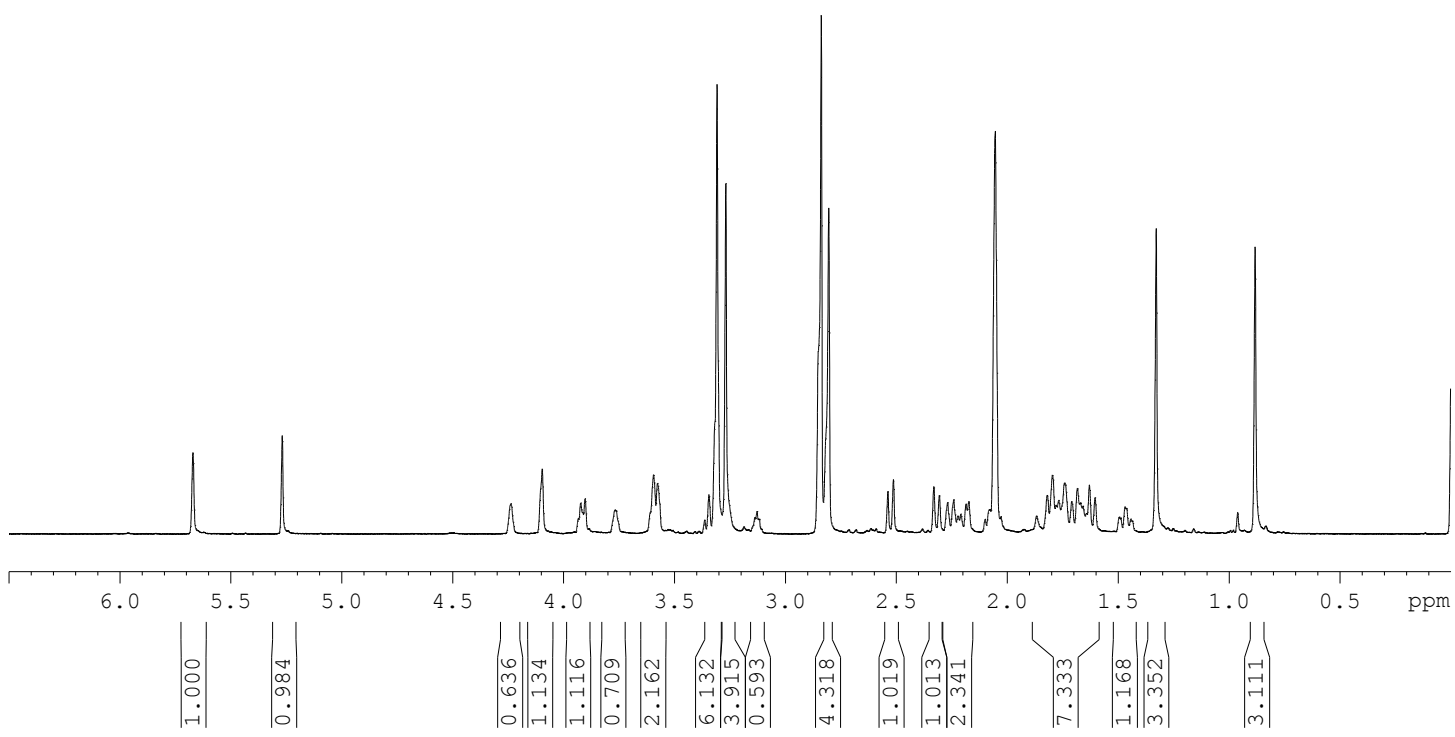


Figure S23. ${ }^{13} \mathrm{C}$ NMR spectrum $(125 \mathrm{MHz})$ of compound 4 in acetone- $d_{6}$.

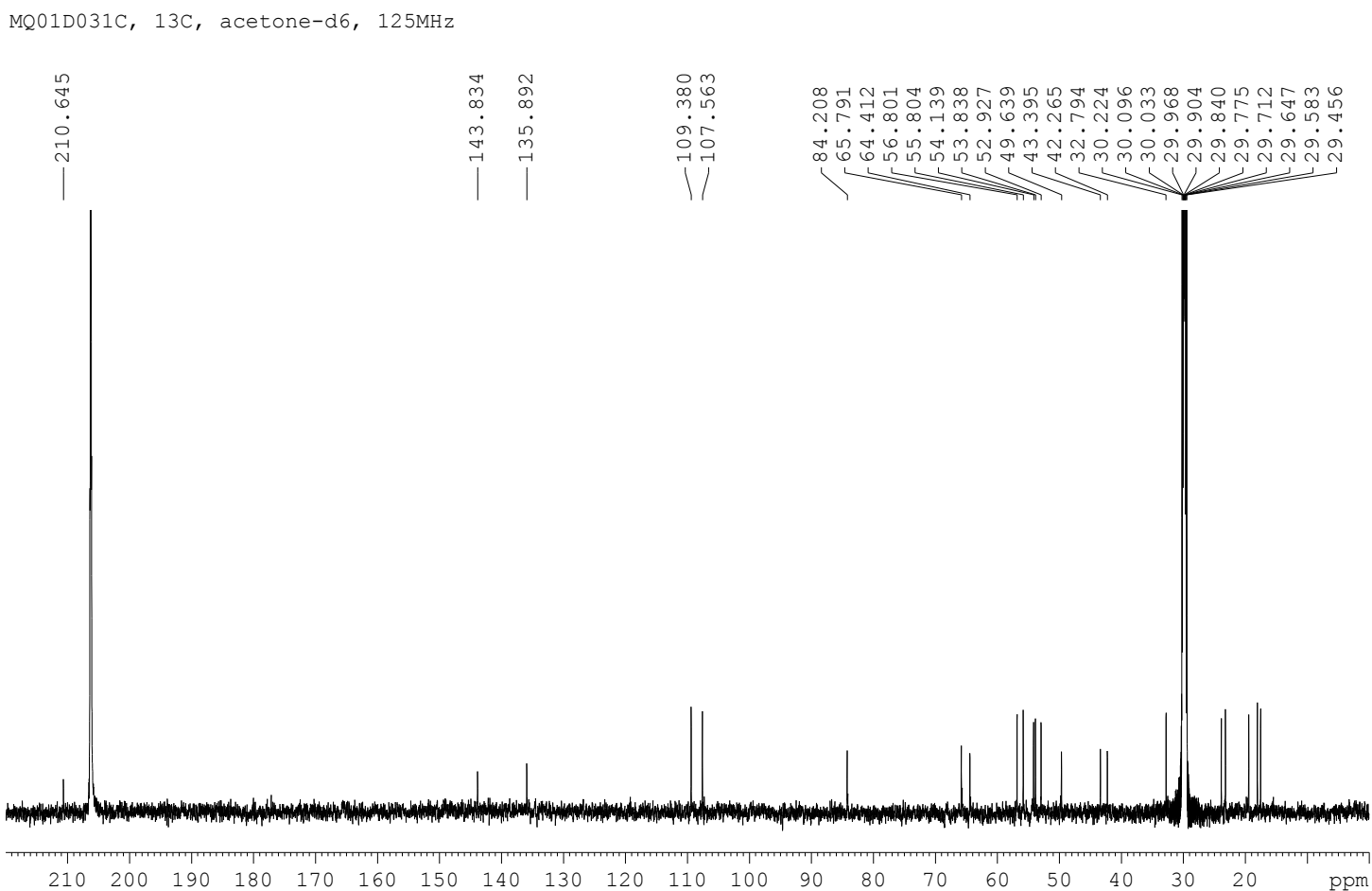

Figure S24. HMQC spectrum of compound 4 in acetone- $d_{6}$.

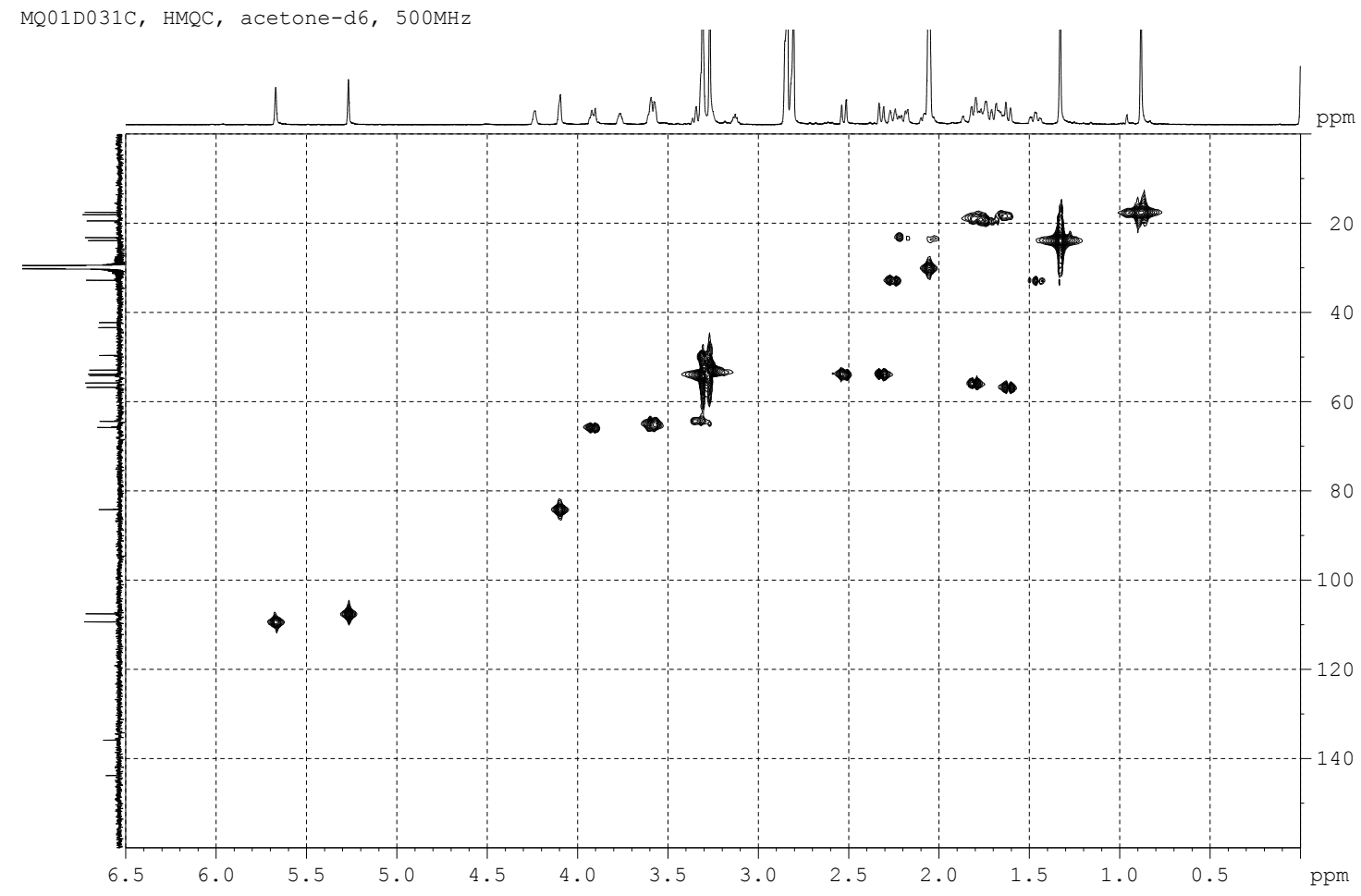


Figure S25. HMBC spectrum of compound 4 in acetone- $d_{6}$.



Figure S26. COSY spectrum of compound 4 in acetone- $d_{6}$.

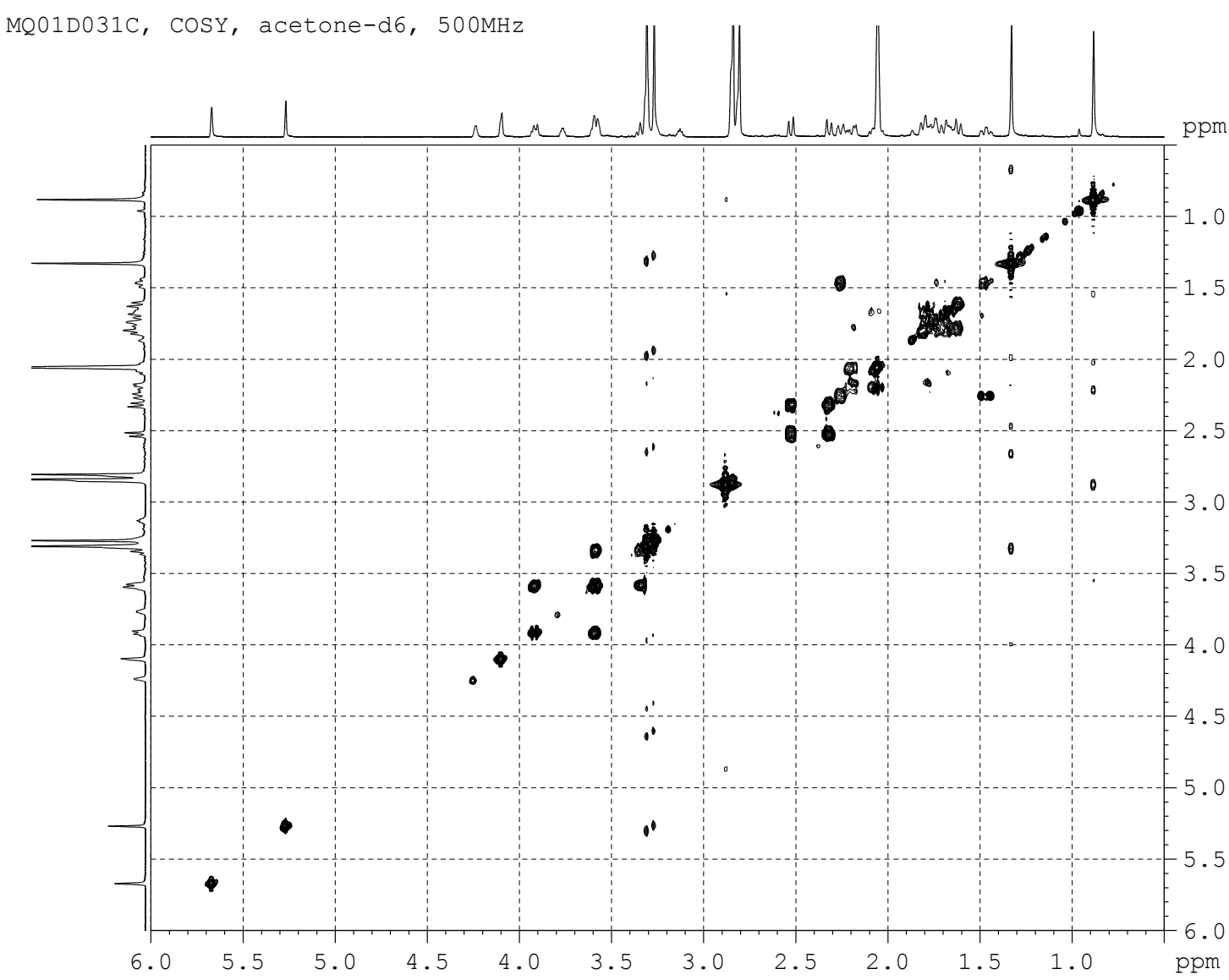


Figure S27. NOESY spectrum of compound 4 in acetone- $d_{6}$.

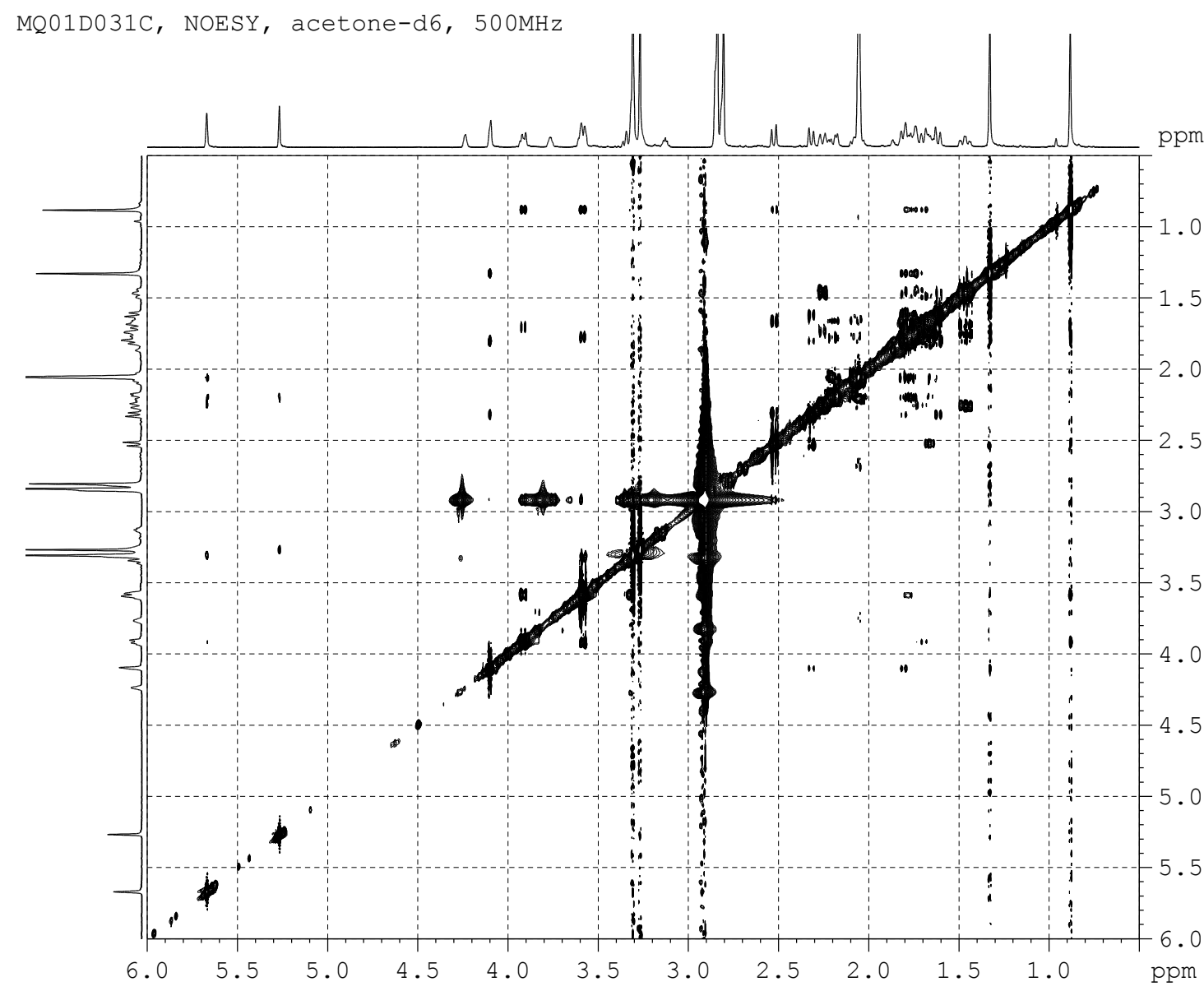

Figure S28. HRESIMS spectrum of compound 4.

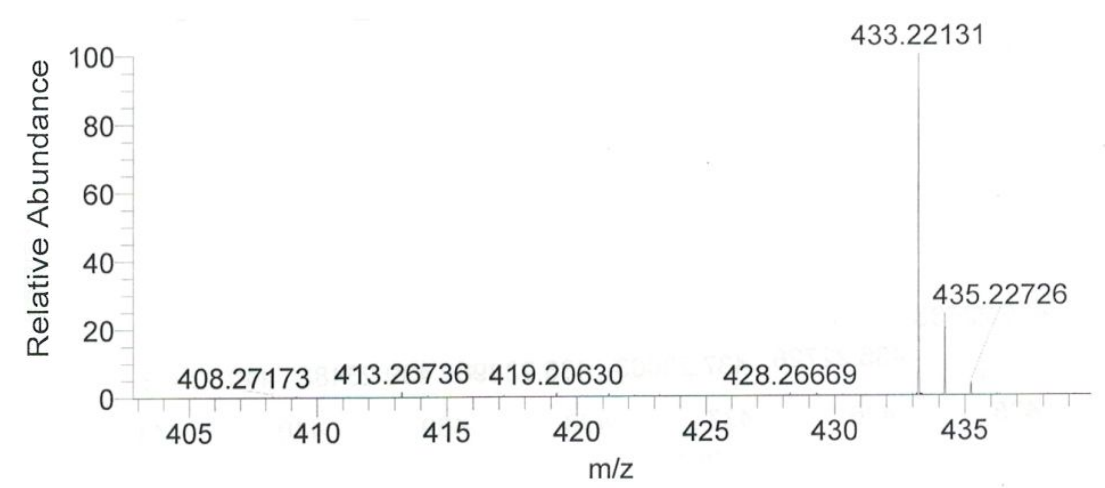

NL: $2.30 E 6$

02-07\#1685 RT:

5.70 AV: $1 \mathrm{~T}$ :

FTMS $\{1,1\}+p$

ESI Full ms

$[200.00-750.00]$

$\mathrm{pm}$ 
Figure S29. ${ }^{1} \mathrm{H}$ NMR spectrum $(600 \mathrm{MHz})$ of compound 5 in acetone- $d_{6}$.

MQ01D032C, 1H, acetone-d6, 600MHz

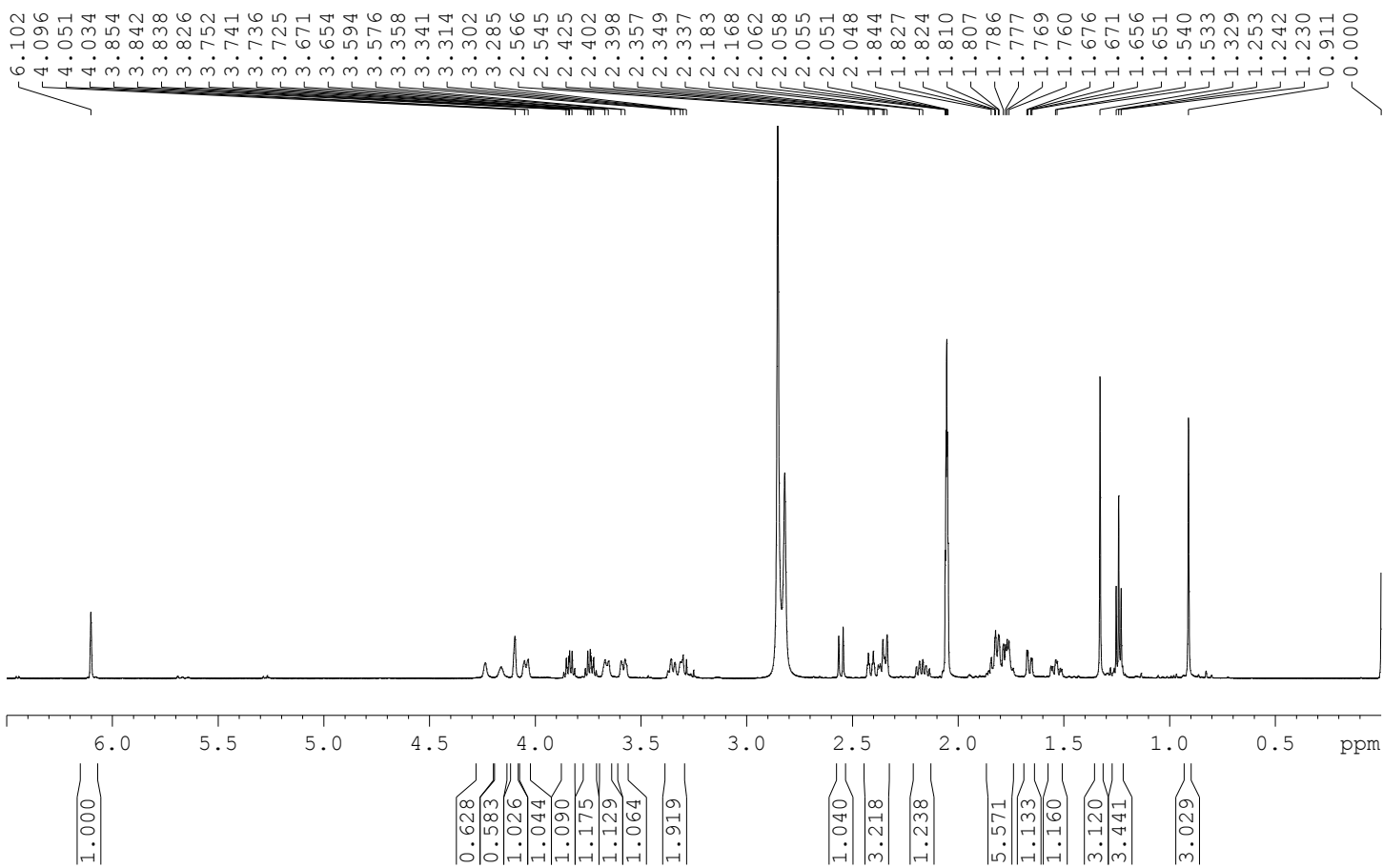

Figure S30. ${ }^{13} \mathrm{C}$ NMR spectrum $(150 \mathrm{MHz})$ of compound 5 in acetone- $d_{6}$.

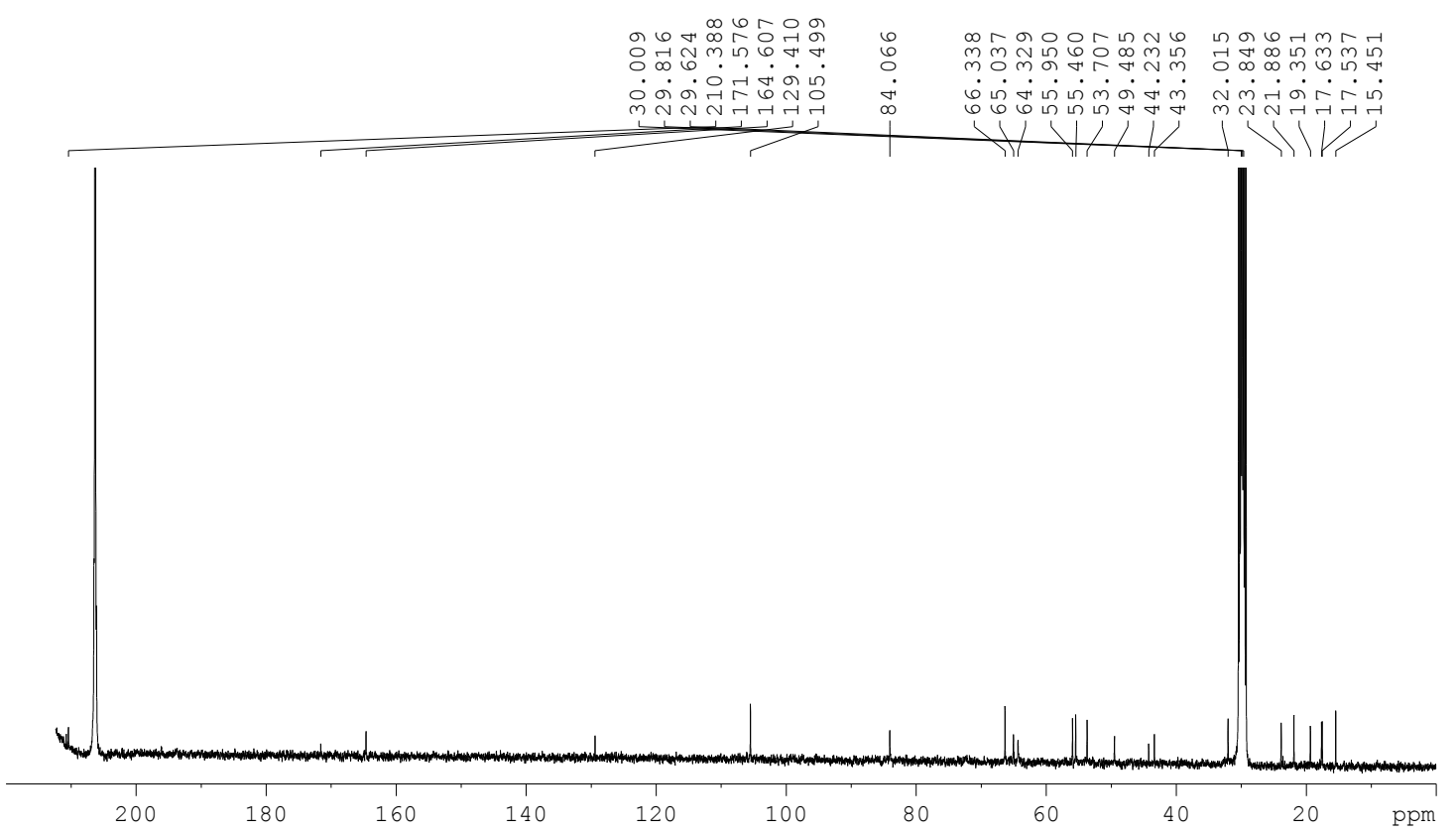


Figure S31. HMQC spectrum of compound 5 in acetone- $d_{6}$.

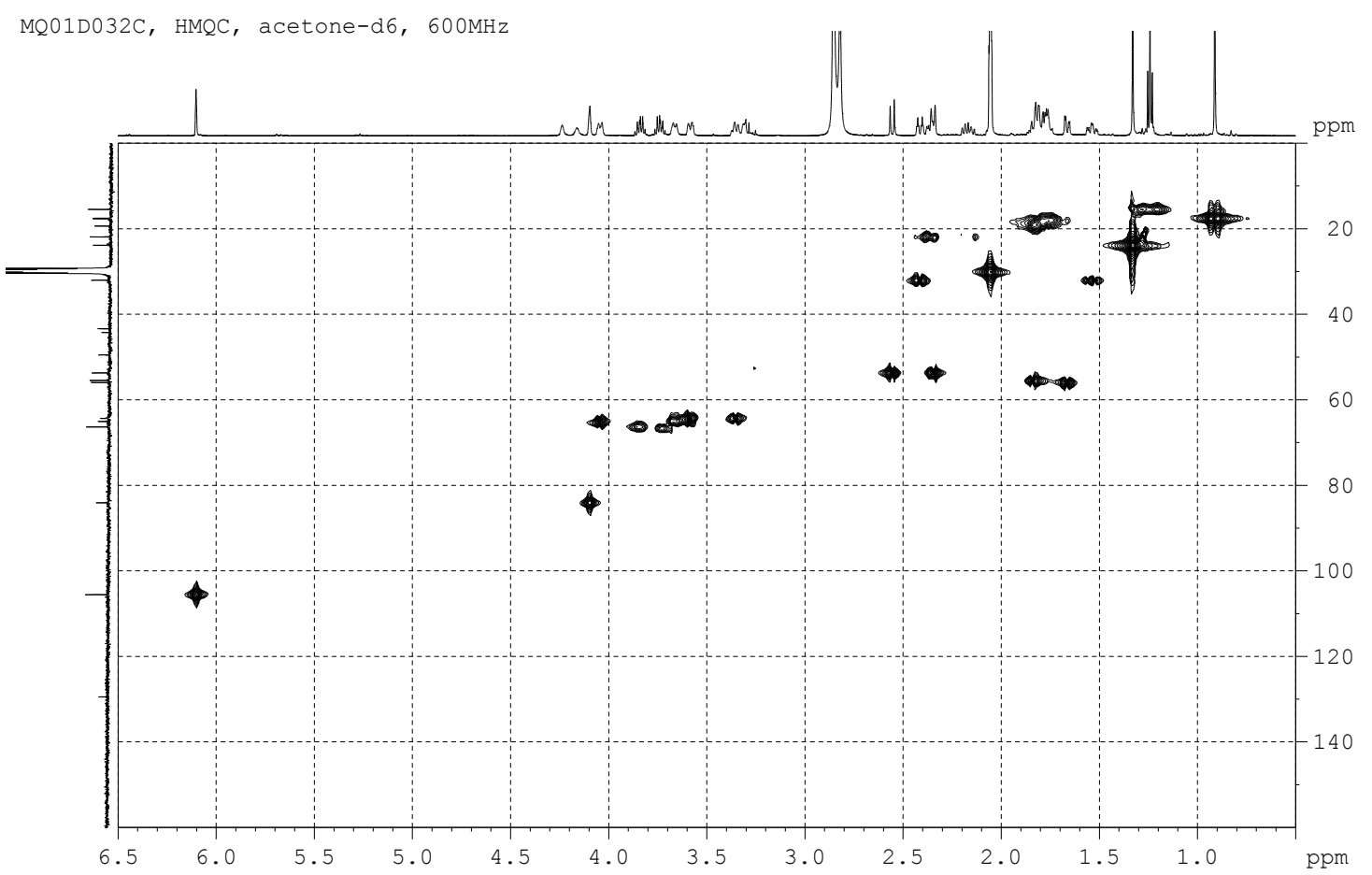

Figure 32. HMBC spectrum of compound 5 in acetone- $d_{6}$.

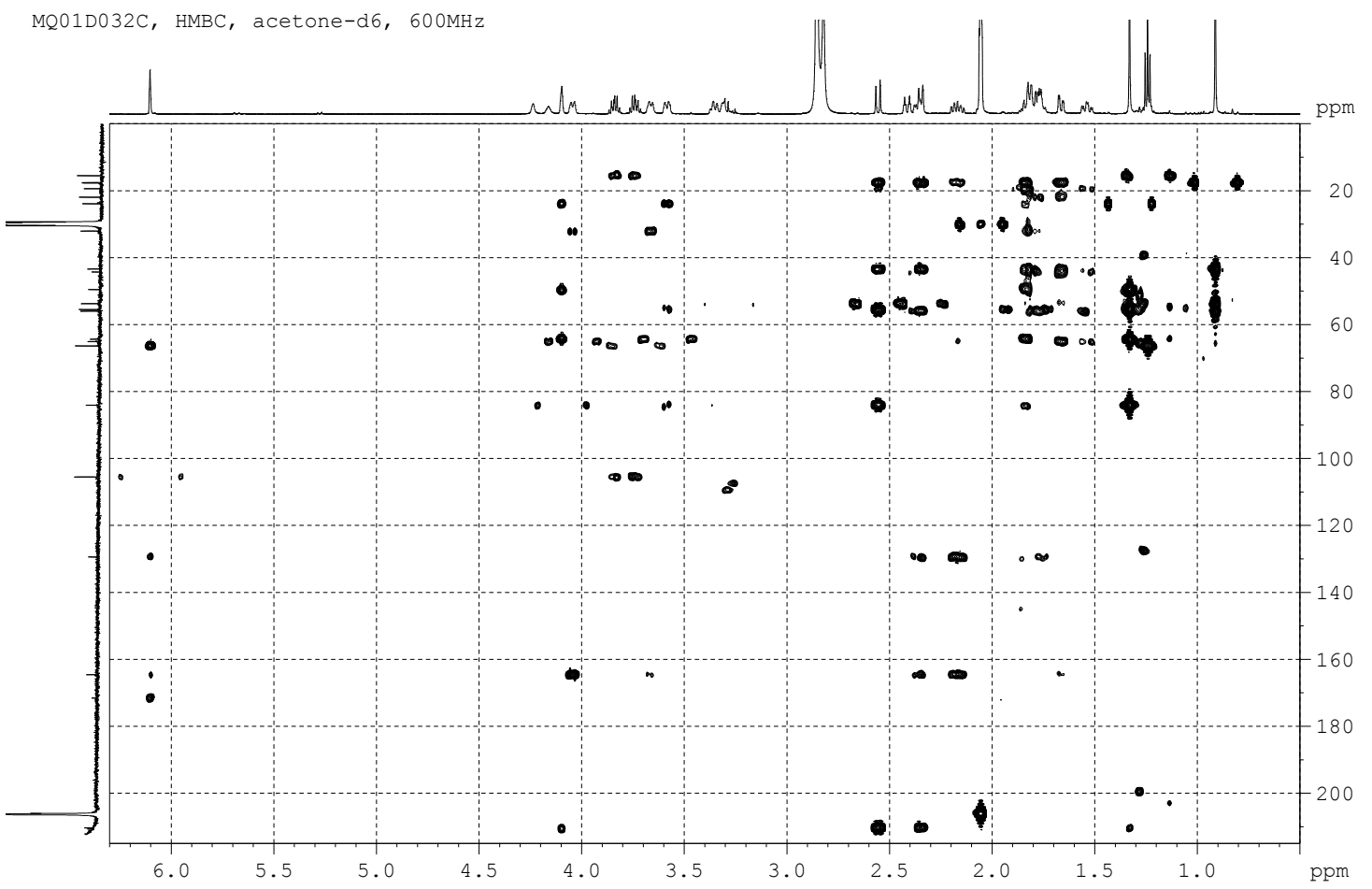


Figure S33. COSY spectrum of compound 5 in acetone- $d_{6}$.

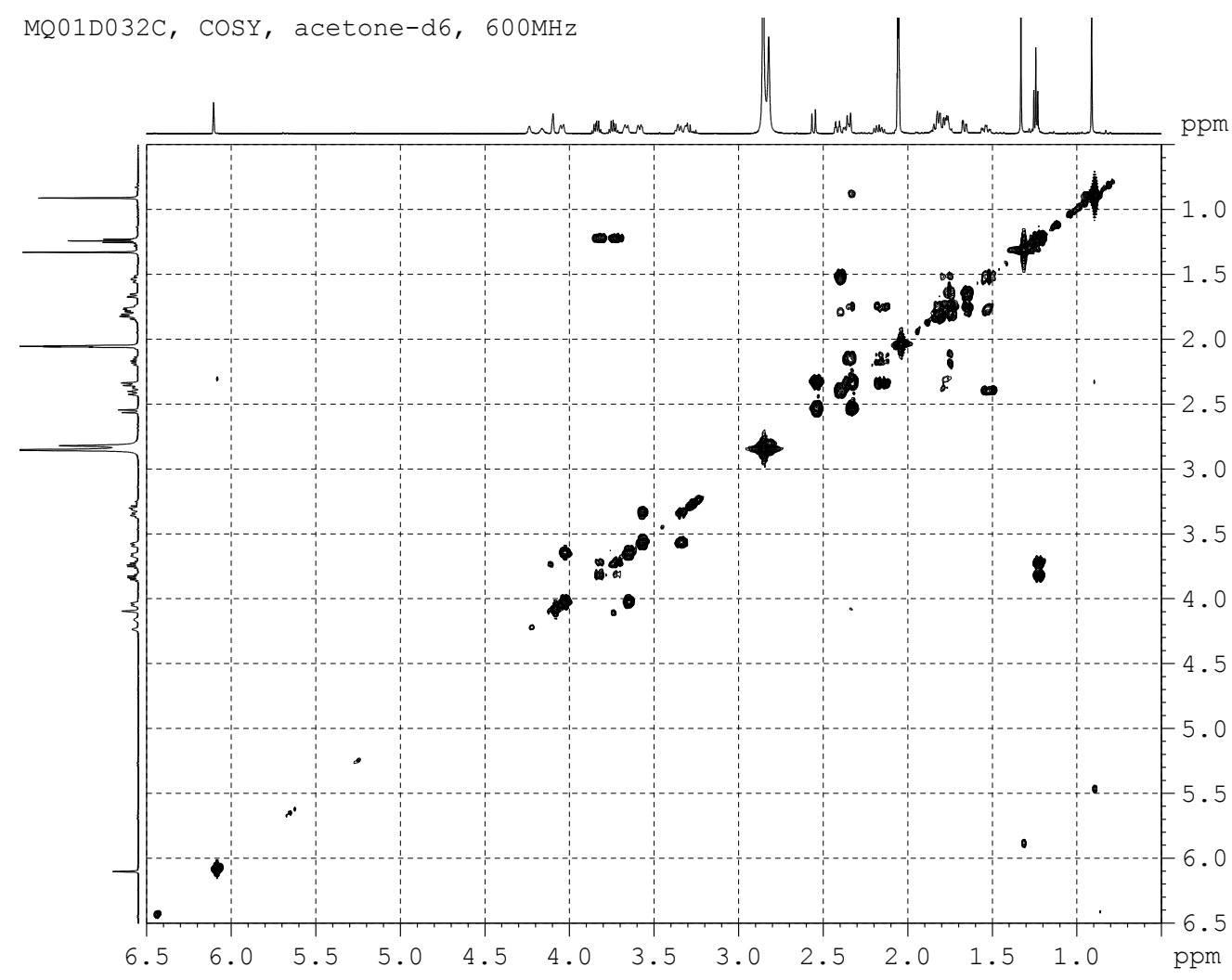

Figure S34. NOESY spectrum of compound 5 in acetone- $d_{6}$.

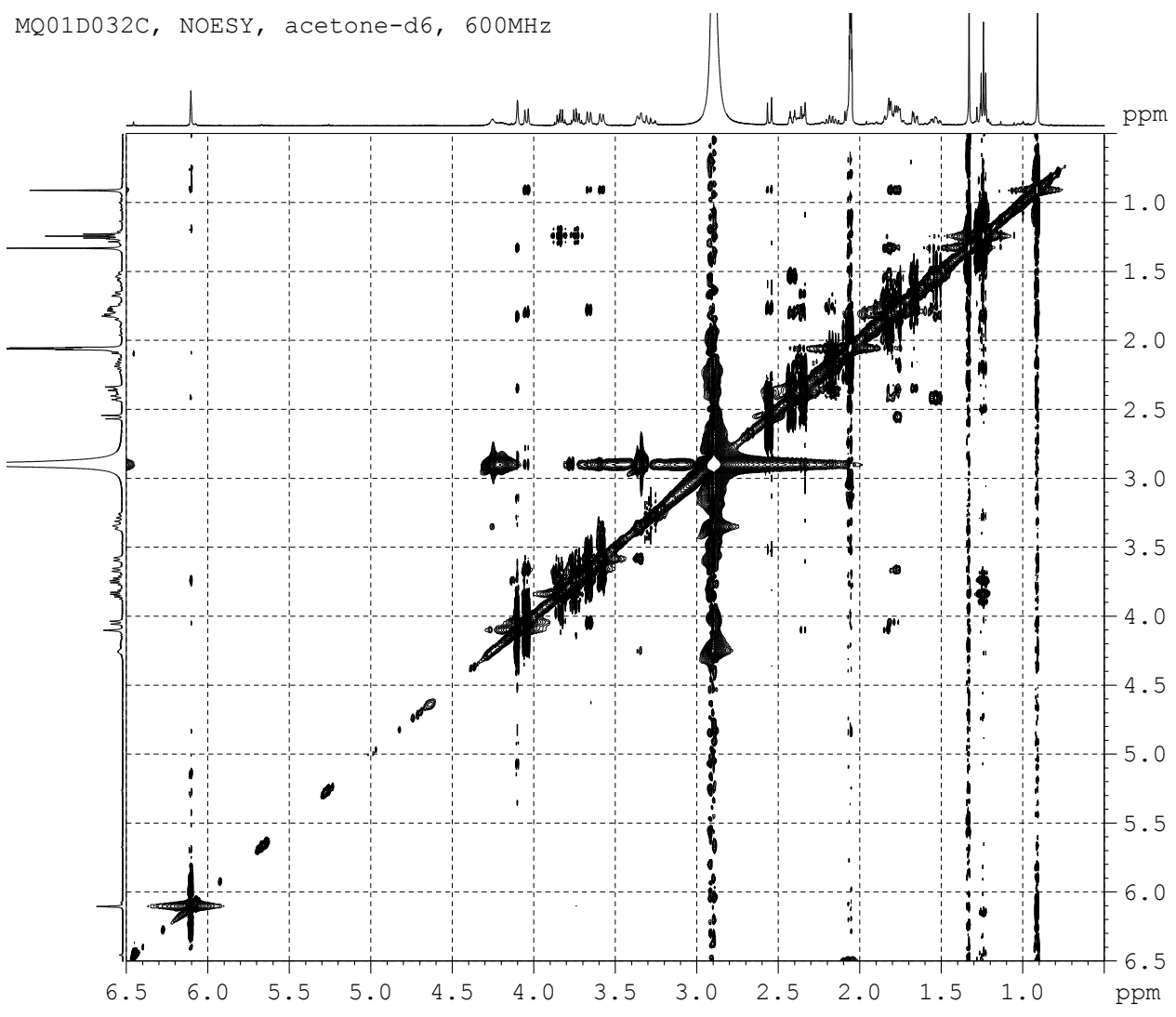


Figure S35. HRESIMS spectrum of compound 5.

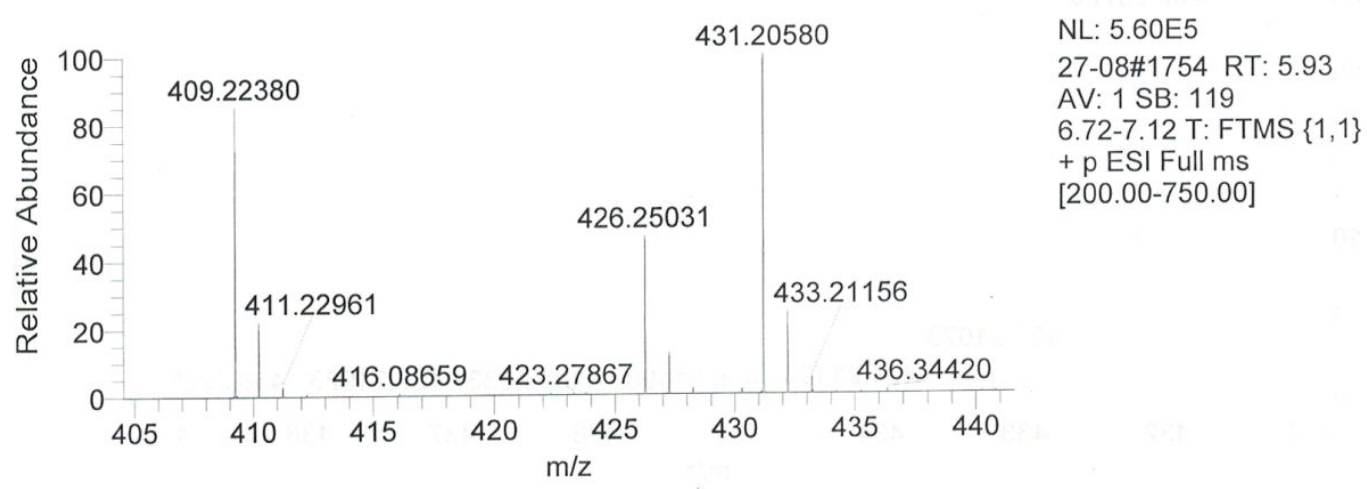

Figure S36. Experimental and calculated ECD spectra for 1.

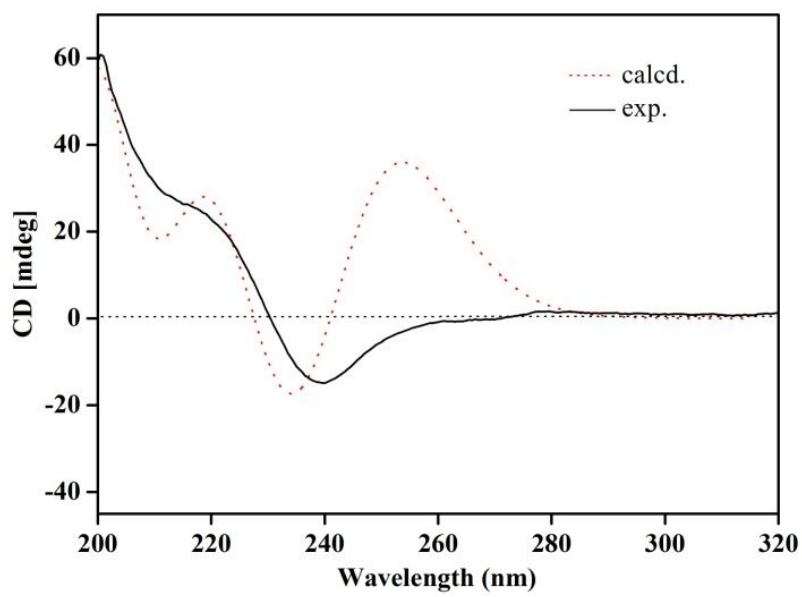

Figure S37. Key NOE correlations and computer-generated models using MM2 force field calculations for $\mathbf{2}$ and $\mathbf{3}$.
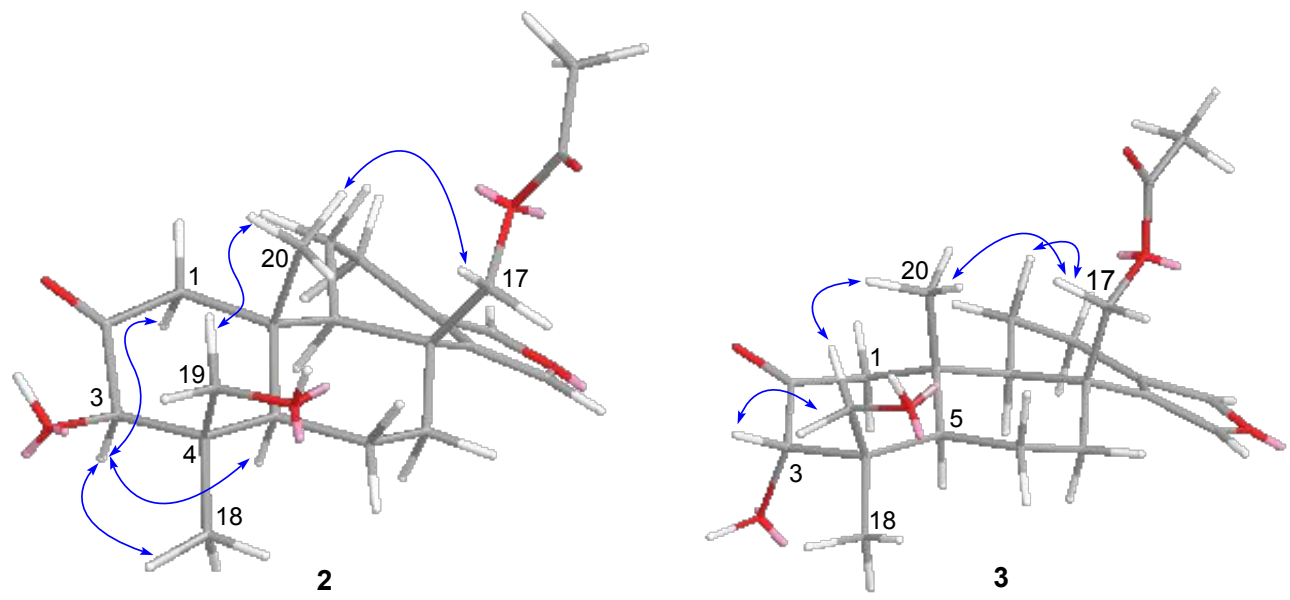
Figure S38. ECD spectra of 2-5, octant rules of 2-4, and helicity rule of 5 .
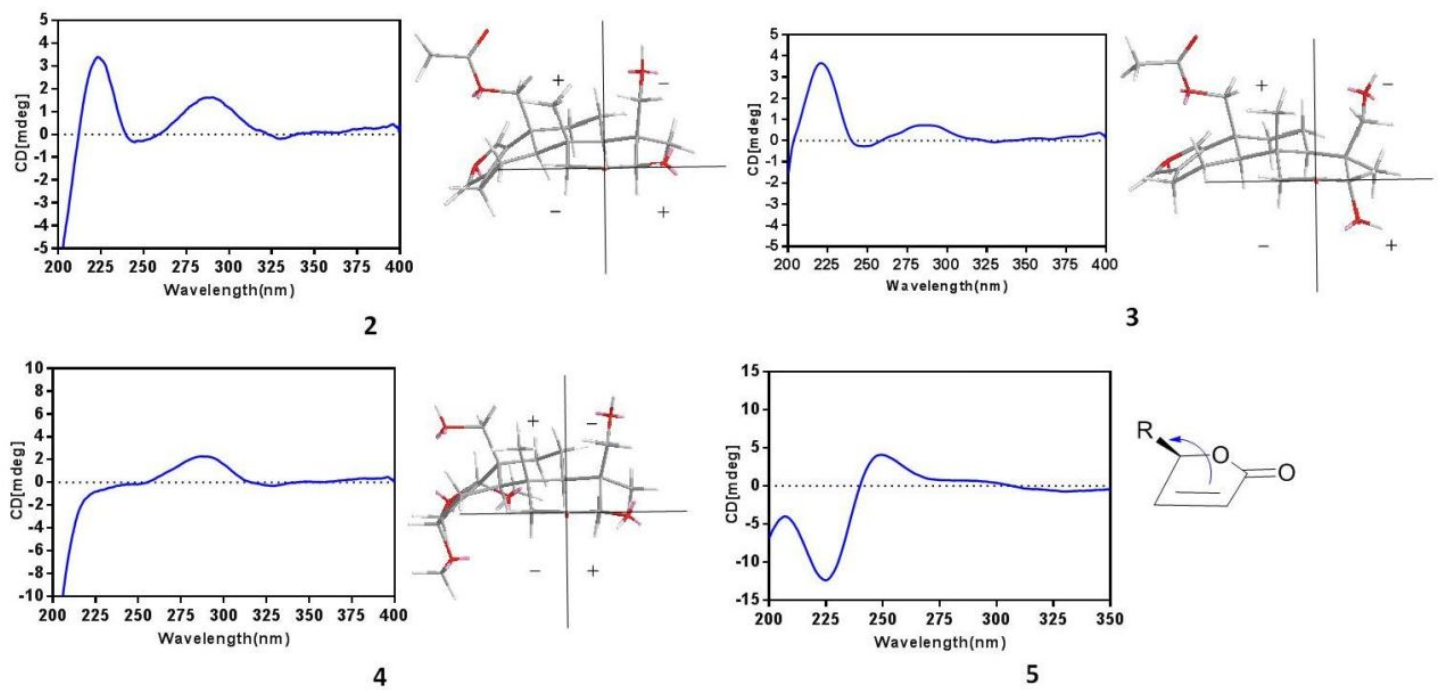